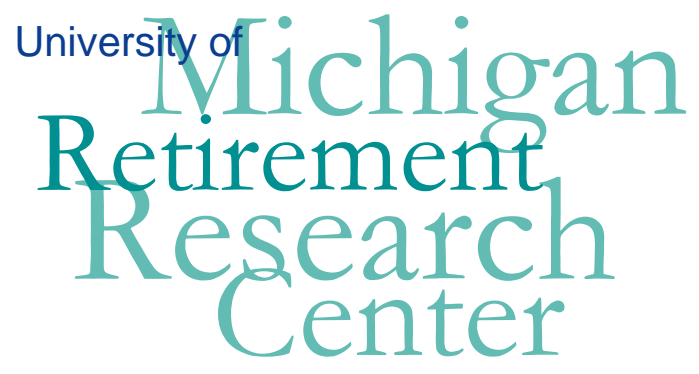

Working Paper WP 2008-183

Early Retirement, Labor Supply, and Benefit Withholding: The Role of the Social Security Earnings Test

Hugo Benĩtez-Silva and Frank Heiland

\begin{tabular}{|l|l|}
\hline $\mathrm{M}$ & $\mathrm{R}$ \\
\hline $\mathrm{R}$ & $\mathrm{C}$ \\
\hline
\end{tabular}$\quad$ Project \#: UM08-09 


\title{
Early Retirement, Labor Supply, and Benefit Withholding: The Role of the Social Security Earnings Test
}

\author{
Hugo Benĩtez-Silva \\ SUNY-Stony Brook \\ Frank Heiland \\ Florida State University
}

September 2008

\author{
Michigan Retirement Research Center \\ University of Michigan \\ P.O. Box 1248 \\ Ann Arbor, MI 48104 \\ http://www.mrrc.isr.umich.edu/
}

(734) 615-0422

\section{Acknowledgements}

This work was supported by a grant from the Social Security Administration through the Michigan Retirement Research Center (Grant \# 10-P-98362-5-04). The findings and conclusions expressed are solely those of the author and do not represent the views of the Social Security Administration, any agency of the Federal government, or the Michigan Retirement Research Center.

\section{Regents of the University of Michigan}

Julia Donovan Darrow, Ann Arbor; Laurence B. Deitch, Bingham Farms; Olivia P. Maynard, Goodrich; Rebecca McGowan, Ann Arbor; Andrea Fischer Newman, Ann Arbor; Andrew C. Richner, Grosse Pointe Park; S. Martin Taylor, Gross Pointe Farms; Katherine E. White, Ann Arbor; Mary Sue Coleman, ex officio 


\title{
Early Retirement, Labor Supply, and Benefit Withholding: The Role of the Social Security Earnings Test
}

\author{
Hugo Benĩtez-Silva and Frank Heiland
}

\begin{abstract}
The labor supply and benefit claiming incentives provided by the early retirement rules of the Social Security Old Age benefits program are of growing importance as the Normal Retirement Age (NRA) increases to 67, the labor force participation of Older Americans rises, and a variety of reforms to the Social Security system are considered. Any reform needs to take into account the effects and rationale of the Social Security Earnings Test and the Actuarial Adjustment Factor. We describe these incentives, and analyze benefit withholding patterns using data from the Master Beneficiary Files of the Social Security Administration, and present descriptive and exploratory evidence on the determinants of benefit withholding using data from the Health and Retirement Survey. We then investigate the importance of the Earnings Test limits for work and claiming behavior using a dynamic life-cycle model of labor supply, benefit claiming, and withholding. We use the latter framework to compare the consequences of a number of changes to the Earnings Test provision for the labor supply behavior and earnings of older Americans.
\end{abstract}

\section{Authors' Acknowledgements}

We are grateful to a number of employees of the Social Security Administration who have patiently answered our questions. Among those individuals we are especially thankful to Barbara Lingg, Christine Vance, Rona Blumenthal, and Joyce Manchester for their time, and for their insights into a number of the issues discussed in this paper. We are grateful to the Social Security Administration and MRRC for funding our work through grant UM08-09. Benĩtez-Silva is also grateful for the financial support on a related project from NIH grant 5 P01 AG022481-04, the Spanish Ministry of Science and Technology through project number SEJ2005-08783-C04-01. Benĩtez-Silva: Economics Department, SUNY-Stony Brook, Stony Brook, N.Y. 11794-4384, phone: (631) 632-7551, fax: (631) 632-7516, e-mail: hugo.benitez-silva@sunysb.edu Heiland: Economics Department, Florida State University, Tallahassee, FL 32306-2180, phone: (850) 644-7083, fax: (850) 644-4535, e-mail: fheiland@fsu.edu 


\section{Introduction}

Social Security provides fairly complex incentives that affect the earnings, labor supply and monthly benefit amounts of individuals who are eligible for Social Security Old Age (SSOA) benefits. Most individuals are currently claiming benefits before the Normal Retirement Age (as of November of $2007,70.9 \%$ of men and $75.7 \%$ of women in the U.S. claimed Social Security benefits before the NRA), and around $7 \%$ of them work and earn enough such that their benefits are reduced due to the Social Security Earnings Test (SSET). The number of older Americans affected by the SSET is likely to increase dramatically in the coming years. This is due to the scheduled increases in the Normal Retirement Age (NRA).

Two of the most important incentives of the system are the SSET, which determines the maximum level of earnings that do not result in a benefit reduction for individuals who have claimed retirement benefits before the NRA, and the Actuarial Reduction Factor (ARF), which determines the reduction in benefits that individuals face if they claim benefits early. The ARF is adjusted after the NRA for benefits withheld due to earnings above the SSET limit (see Gustman and Steinmeier (1991), Myers (1993, p. 52), Gruber and Orszag (1999, 2000)) providing a greater incentives for individuals to claim benefits early and for individuals who claimed benefits early and had some benefits withheld-to work and earn above the SSET limit before the NRA (see Benítez-Silva and Heiland (2007, 2008), Benítez-Silva, Dwyer, Heiland, and Sanderson (2008)).

While the amount of benefits withheld due to earnings in excess of the SSET limit is the crucial variable in these rules, very little is known about individuals' actual benefit withholding patterns and the characteristics of those who experience it. In this paper we analyze benefit claiming and withholding patterns using several data sources and techniques. We investigate the characteristics of individuals who claim benefits early and continue to work or return to the labor force after a leisure spell and earn above the SSET limit. We provide evidence regarding such effects from analyzes of benefit withholding data and simulation of a dynamic life-cycle retirement model. A better understanding of who is affected by the SSET will help to make better predictions regarding

benefit take-up, work behavior, and SSET revenues under the scheduled increases in the NRA, and 
other important reform scenarios currently considered in the debate of securing long-term solvency of Social Security. Properly identifying those that are less likely to work after claiming benefits will also provide a quantitative measure of the possible induced entry effect into the SSDI or SSI program if the Early Retirement Age were to be increased.

The next section describes in some detail the incentives provided by Social Security between the ERA and the NRA, and discuss their implications for claiming behavior, earnings, and benefits withholding patterns using data from the Master Beneficiary Files of the Social Security Administration. We also present descriptive and exploratory results on the determinants of benefit withholding conditions using data from the Health and Retirement Survey. We then investigate the importance of the Earnings Test limits for work and claiming behavior using a dynamic life-cycle model of labor supply, benefit claiming, and withholding. We use the latter framework to compare the consequences of a removal of the Earnings Test to a reduction of the tax rate and an increase in the earnings limit, for the labor supply behavior and earnings of older Americans. The final section concludes.

\section{Social Security Incentives for Early Retirement}

Individuals who claim benefits before the NRA but continue to work or reenter the labor force can reduce the early retirement penalty by suspending benefit payments. ${ }^{1}$ The Actuarial Reduction Factor (or early retirement reduction factor), in turn, will be increased proportionally to the number of months without benefits, which will increase benefits permanently after the individual reaches the NRA. Given a NRA of 66, which will be the prevailing one for the cohort born between 1943 and 1954, the Actuarial Reduction Factor is a number between 0.75 and 1 depending on when the individual claims benefits, and how many months he or she earns above the Earnings Test after

\footnotetext{
${ }^{1}$ In this paper we are not considering spousal benefits and joint decision making in the household. The complexities introduced by those considerations are out of the scope of this analysis. By ignoring spousal benefits we are not taking into account the fact that approximately $5.96 \%$ of the individuals who receive some type of Old Age, Survivors, or Disability Insurance (OASDI) benefits receive them as spouses of entitled retirees. This percentage comes from the Public-Use Microdata File provided by the Social Security Administration and refers to a $1 \%$ random sample of all beneficiaries as of December of 2001.
} 
claiming benefits. This adjustment of the ARF allows those who become beneficiaries before the NRA to partially or completely reverse the financial consequences of their decision, averting being locked-in at the reduced rate. In the sequel of this section the exact details of these incentives are presented.

\subsection{Benefit Calculation}

Individuals aged 62 or older who had earned income that was subject to the Social Security payroll tax for at least 10 years since 1951 are eligible for retirement benefits under the Old Age benefits program. Earnings are subject to the tax up to an income maximum that is updated annually according to increases in the average wage. To determine the monthly benefit amount (MBA), the Social Security Administration calculates the Primary Insurance Amount (PIA) of a worker as a concave piece-wise linear function of the worker's average earnings subject to Social Security taxes taken over her 35 years of highest earnings. If the benefits are claimed at the NRA (66 for those born between 1943 and 1954), the MBA equals the PIA. If an individual decides to begin receiving benefits before the NRA and exits the labor force or stays below the earnings limit, her MBA is reduced by up to $25 \%$, assuming a NRA of 66 . Under the current regulation of the OA program, the monthly benefit amount received upon first claiming benefits depends on the age (month) of initiation of Social Security benefits, in the following way,

$M B A_{t}=\left\{\begin{aligned}(0.75+ & \left.0.05 * \frac{1}{12} *(\text { Months not claimed in the period prior to } 3 \text { years before NRA })\right) * P I A \\ & \text { if claimed more than } 3 \text { years before NRA; } \\ (0.80+ & \left.0.20 * \frac{1}{36} *(\text { Months not claimed in } 3 \text { years before NRA })\right) * P I A \\ & \text { if claimed within the } 3 \text { years before NRA. }\end{aligned}\right.$

where $M B A_{t}$ represents the monthly benefit amount before the NRA (see SSA-S 2005, p.18). Assuming that the individual continues to receive benefits, her $M B A_{t}$ is permanently reduced. The 
Actuarial Reduction Factor (ARF) underlying this calculation is a permanent reduction of benefits by $5 / 9$ of 1 percent per month for each month in which benefits are received in the three years immediately prior to the NRA. The reduction of benefits is $5 / 12$ of 1 percent for every month before that. Thus, the maximum actuarial reduction will reach 30 percent as the NRA increases to 67 over the next few years (see SSA-S 2005, p.18). The reductions in benefits for early claimers are designed to be approximately actuarially fair for the average individual. During the post-NRA period additional adjustments exist: Workers claiming benefits after the NRA earn the delayed retirement credit (DRC). For those born in 1943 or later it is $2 / 3$ of 1 percent for each month up to age 70 which is considered actuarially fair. For those born before 1943 it ranges from 11/24 to 5/8 of 1 percent per month, depending on their birth year.

\subsection{Actuarial Reduction Factor}

One less-emphasized feature of the process of benefit reduction due to early retirement is the possibility to reduce the penalty even after initiating the receipt of benefits. The specifics of this adjustment to the Actuarial Reduction Factor are documented in the Social Security Handbook (SSA-H, §724. Basic reduction formulas, §728. Adjustment of reduction factor at FRA) and in the internal operating manual used by Social Security field employees when processing claims for Social Security benefits (SSA-M, RS00615. Computation of Monthly Benefits Amounts) but may not be well-understood by the retirees. To illustrate this feature of the system, suppose the NRA is 66 years, and an individual claims benefits at age 62 and $n$ months, where $n<<48$, receives checks for $x$ months where $(n+x<<48)$, and suspends receiving checks after that until she turns 66 (after which she retires for good). In this case she receives $x$ checks of

$$
M B A_{t}= \begin{cases}\left(0.75+0.05 * \frac{1}{12} * n\right) * P I A & \text { if claimed more than } 3 \text { years before NRA; } \\ \left(0.80+0.20 * \frac{1}{36} * n\right) * P I A & \text { if claimed within the } 3 \text { years before NRA }\end{cases}
$$


After turning 66, her $M B A$ will be permanently increased to

$$
M B A_{t}=\left[0.75+\left(0.20 * \frac{1}{36} * n\right)+\left(0.20 * \frac{1}{36} *(36-n-x)\right)+0.05\right] * P I A .
$$

It is important to note that the adjustment of the ARF is automatic and becomes effective only after reaching the NRA.

\subsection{Earnings Test}

The Earnings Test limit defines the maximum amount of income from work that a beneficiary who claims benefits before the NRA under OASI may earn while still receiving the "full" $M B A$. Some sources of income do not count under the Earnings Test. For details see SSA-H $§ 1812$. Notice that retirement contributions by the employer do not count towards the limit, but additional contributions by the employee even if they are through a payroll deduction are counted. This means that individuals earning above the limit cannot just increase their retirement savings to avoid being subject to the limit. We thank Barbara Lingg and Christine Vance from the Social Security Administration for clarifying this point, which is rarely discussed in any publication. Earnings above the limit are taxed at a rate of 50 percent for beneficiaries between age 62 and the January of the year in which they reach the NRA, and 33 percent from January of that year until the month they reach the NRA (SSA-S 2005, p.19; SSA-S 2005, Table 2.A18). For the latter period, the earnings limit is higher, $\$ 33,240$, compared with $\$ 12,480$ for the earlier period as of 2006 (as of 2008 the limits are $\$ 13,560$ and $\$ 36,120$ ). Starting in 2000 , the Earnings Test was eliminated for individuals over the NRA.

Individuals who continue or reenter employment after claiming Social Security benefits before the NRA, and whose earning power or hours constraints are such that their income from work is around or below the earnings limit, are mailed their full monthly check from Social Security and are locked-in at the reduced benefit rate permanently. Those with earnings above the limit will not receive checks from Social Security for some months and thereby adjust their ARF. Notice that 
a beneficiary may receive a partial monthly benefit at the end of the tax year if there are excess earnings that do not completely offset the monthly benefit amount (see SSA-H, §1806). Individuals have the option of informing Social Security to suspend the monthly benefit payment at any time if they believe they will be making earnings high enough above the Earnings Test. However, during the first year after claiming benefits, the Social Security Administration performs a monthly test to determine whether the person should receive the monthly check. As a result an early claimer who is not working or earns below the limit in the months after claiming ("grace year") will receive all monthly benefits even if earnings for that calendar year exceed the Earnings Test limit due to high earnings before claiming.

Social Security claim specialists emphasized to us that during the first year after claiming they do what is most advantageous to the claimer, the monthly or the yearly test, if they have enough information. However, they failed to clarify what that means. Some of them said the number of checks individuals receive is maximized, but we were unable to find documentation of such practices. In any case, the internal operating instructions used by Social Security field employees when processing claims for Social Security benefits state that the monthly Earnings Test only applies for the calendar year when benefits are initiated unless the type of benefit changes (see SSA-M, RS02501.030). After the first year, the test is typically yearly and it depends on the expected earnings of the individual. Given the scarce documentation of the functioning of the ARF, having earned above the earnings limit, and thus receiving fewer checks, may be a common way for beneficiaries to learn about the possibility of undoing the early retirement penalty.

\subsection{Hypothesis}

The possibility of affecting the Actuarial Reduction Factor (ARF) provides an incentive to claim benefits before the NRA even if the individual expects to continue to work (or to return to work) since having claimed benefits provides a type of insurance. Consistent with this hypothesis, Benítez-Silva and Heiland (2007) develop a dynamic model of retirement that accounts for health and income shocks and show that when individuals have the option to affect the reduction factor 
after claiming early, the proportion of individuals who claim benefits at 62 increases significantly. Benítez-Silva, Dwyer, Heiland, and Sanderson (2008) use a similar dynamic model of retirement but also account for Social Security reform expectations, that is the perceived likelihood that future benefits will be cut. With this additional source of uncertainty in the model, they are able to explain the large proportion of Americans claiming benefits early.

In addition to the incentive to claim benefits earlier, the rules discussed above are also expected to affect the decision to work. Given that the reduction factor is not adjusted instantaneously for benefits that are withheld between benefit initiation and the NRA, it is only actuarially fair for early claimers who have either all or none of their benefits withheld during that time. Some individuals will drop out of the labor force soon after claiming or earn consistently below the Earnings Test limit throughout after claiming. Consistent with these predictions, Benítez-Silva and Heiland (2007) and Benítez-Silva and Heiland (2008) find that individuals who claimed benefits are less likely to drop from the labor force than individuals who have not claimed benefits and continue to work, and that this effect weakens as individuals approach their NRA.

Individuals are also expected to be more likely to work and to experience benefit withholding due to the SSET if they have higher earnings power. Since benefits withheld due to the Earnings Test increase the ARF only after reaching the NRA, the resulting benefit flow can be actuarially unfair for early claimers, providing an incentive for individuals who have benefits withheld to continue to work and earn above the SSET limit. This incentive is weaker for individuals with below-average life expectancy (individuals who are less willing to trade off present for future benefits). As a result, we expect that respondents with poorer overall health and those who experience health limitations that affect their ability to work are less likely to have benefits withheld due to earnings.

If individuals are unaware of the fact that benefits withheld due to earnings are not lost but lead to a higher benefit rate after the NRA, then they may only respond to the taxation incentive of the Earnings Test and be less likely to claim benefits early when they expect to continue to work and try to remain below the SSET limit if they claimed early (see Benítez-Silva and Heiland (2008)). This 
would suggest that individuals with greater financial knowledge are expected to be more likely to respond to the full incentives provided by the SSET and the ARF, thus more likely to claim before the NRA and earn above the SSET limit. ${ }^{2}$ Consistent with this idea, Friedberg (1998 and 2000), in studies on the effect of changes in the Earnings Test rule prior to 2000 on labor supply, finds that up to $5 \%$ of individuals bunch just below the Earnings Test limit and appear to adjust with the Earnings Test limit. On the other hand, a recent analysis of labor force exit behavior in a sample of individuals from the Health and Retirement Study (HRS) produced evidence that early claimers who do not withdraw from the labor force around the time they claim are increasingly likely to stay in the labor force (see Benítez-Silva and Heiland (2007, 2008)), consistent with the full incentives provided by the SSET and the ARF.

\section{Evidence from Social Security Benefit Withholding Data}

The Social Security Administration provides information on beneficiaries based on the Master Beneficiary Record (MBR), a database of all beneficiaries, as well as a $10 \%$ and a $1 \%$ random sample of the MBR. To illustrate the incidence of adjustments to the Actuarial Reductions Factor, some estimates of overall trends and distribution of benefit withholding based on the $1 \%$ sample taken from the Annual Statistical Supplements of 2000 to 2007 (Table 6.B1) are presented in Figure 1.

The aggregate evidence based on Social Security's Master Beneficiary Record (MBR) illustrates the importance of benefit adjustments among recent cohorts of retirees. Among the $1,224,100$ individuals who turned 62,63 or 64 and initiated early retirement benefits in 2006, the most recent year available, 74,500 saw some or all of their monthly checks withheld due to the Earnings Test in that year (first panel), and therefore had their actuarial reduction factor affected by their labor supply decisions after claiming benefits. The majority of these individuals had half or more of their benefits withheld suggesting that they earned significantly above the Earnings Test

\footnotetext{
${ }^{2}$ See Vroman (1985), Burtless and Moffitt (1985), Honig and Reimers (1989), Leonesio (1990), Reimers and Honig (1993), Reimers and Honig (1996), Baker and Benjamin (1999), and Friedberg (2000).
} 
limit between age 62 and the NRA.

The second panel shows that women are less likely to see their benefits withheld than men. In $2006,6.9 \%$ of men who claimed benefits early saw at least some of their benefits withheld by Social Security compared to $5.3 \%$ of women. This reflects both the lower labor supply and the lower wages of the women in that age group compared to men and is consistent with our hypothesis that individuals with greater earnings power are more likely to experience benefit withholding. The data also show that the fraction of early claimers who experience benefit withholding has decreased by more than 3 percentage points between 1999 and 2002 and has fluctuated between $6 \%$ and $7 \%$ since then. As discussed in Benítez-Silva and Heiland (2007), the decline may reflect worsening labor market conditions for older workers since 2000. As the job prospects deteriorated, fewer early claimers found employment which resulted in fewer cases of earnings above the Earnings Test limit.

The third panel illustrates the incidence of benefit withholding at ages 62, 63 and 64 for male and female beneficiaries combined since 1999. Those claiming at age 63 almost twice as often experienced some withholding of reduced retirement benefits compared to those who claim at 62 . While the incidence rate has fallen slightly among those who claim at 62 or 63, it has fluctuated quite dramatically for those claiming at age 64. It fell from $25.3 \%$ in 1999 to $5.5 \%$ in 2002 but then increased to $11.9 \%$ in 2005 and $10.6 \%$ as of 2006 . This pattern is likely the result of two developments. First, as discussed in Benítez-Silva and Heiland (2007), the initial decline is likely to be the result of the sharp increase in the Earnings Test limit that occurred between 1999 and 2002 for those who work between the January of the year in which they turn 65 and their birthdays. This limit increased from $\$ 15,500$ in 1999 to $\$ 30,000$ in 2002 , suggesting that even in the absence of any behavioral response to the change, the number of individuals affected by the limit would decline considerably. Second, changing labor market opportunities may play a role in these trends for those 62 to 64 . Individuals who initiate early benefits when they are closer to the NRA may be more attached to the labor force than those claiming as soon as they become eligible for reduced benefits. In the environment with fewer employment opportunities in the years 2000-2002, those 
claiming later may have been increasingly likely to withdraw from the labor market compared to the boom years of the late 1990s. Consistent with this, individuals who initiated benefits at age 64 experienced higher levels of withholding after 2002 when the opportunities in the labor market improved.

\section{Individual-Level Evidence on Benefit Withholding}

In this section we examine individuals' characteristics associated with benefit withholding using longitudinal data from the Health and Retirement Survey (HRS). We construct measures of whether individuals may have benefits withheld based on individuals' reports of benefit initiation, benefit receipt, and earnings receipt after claiming. To test the hypotheses discussed above, we estimate multivariate models of potential benefit withholding controlling for a large set of factors that are expected to influence the likelihood that benefits are withheld due to earnings above the Social Security Earnings Test Limit. The set of explanatory variables used is shown in Table . To construct these covariates we assigned characteristics from the closest survey wave available to the month of a person's $62^{\text {nd }}$ birthday.

As proxies of a person's market earnings power we use measures of educational attainment, cognitive ability and work-related health limitations. Together with marital status and subjective life expectancy, poor health may also capture leisure preferences. The availability and type of health insurance, pension wealth, and asset wealth are expected to play an important role in the decisions of when to withdraw from the labor force. Hence we have constructed an indicator for individuals without health insurance and for those with private health insurance. The individual's wealth during this part of the life cycle is measured by net total household wealth, and an indicator for whether they have a private pension.

Using the restricted earnings data from the HRS we have constructed a person's PIA, that is a measure of the respondent's expected Social Security wealth at the NRA based on their history of earnings. The restricted earnings data provide the history of earnings for the 9,472 individuals, as 
of the first wave of interviews, that gave permission to link their files, from 1951 to 1991. Haider and Solon (2000) find little evidence of non-randomness and lack of representativeness in this subsample of individuals. The PIA that employs the individuals' earnings' histories to imputes earnings up to the individuals' $62^{\text {nd }}$ birthday in order to calculate the retirement benefits as of that age. For ease of comparisons we convert it to the level corresponding to age 65 , the NRA for the sample members, using the monthly actuarial adjustment factor and assuming that any earnings collected after 62 do not replace the previous 35 highest earnings years.

We employ two strategies to infer benefit withholding: (i) earnings exceeding the Social Security Earnings Test limits in a given year and (ii) a decline in the monthly amount. Following strategy (i) we construct three binary variables, "Earnings > Limit" at 62, 63, and 64, that are set to 1 if a person's current earnings after claiming exceed the annual limit at age 62, 63, or 64 (and 0 otherwise). ${ }^{3}$ The universe for these measures are individuals who claim before the NRA, and report positive earnings for at least some period after claiming. Based on reported monthly social security benefits over time (expressed in constant 1991 \$s), we construct a binary indicator that equals 1 if a decline in benefits before the NRA occurs (0 otherwise). Given that some degree of measurement error is likely, we only count declines of more than $10 \%$. The universe for this measure are respondents with two valid monthly benefit reports prior to NRA.

As shown in Table 5, looking across these four measures, withholding conditions are met in $7 \%$ to $13 \%$ of the cases, a range in line with the aggregate proportion of benefit withholding observed in 1999 (see Section 2). Notice that our measures do not directly compare to the proportion experiencing withholding by age at benefit initiation in the bottom panel of Figure 1. Our measures based on the earnings' conditions suggest that withholding is more likely to take place at age 63 and 64 than at age 62. This may be because of individuals who claimed benefits early and withdrew from the workforce around that time but subsequently returned to the labor market. This explanation is plausible, especially given that our data span the years 1992-2000, a period when employment prospects improved steadily for all demographics.

\footnotetext{
${ }^{3}$ The relevant annual limits in our samples are those from 1992 to 2000 (in current $\$$ s): 7,440, 7,680, 8,040, 8,160, $8,280,8,640,9,120,9,600$, and 10,080 .
} 
Table 6 reports the marginal effects from probit models of benefit withholding. The results suggest that men are more likely to experience benefit withholding than women. This is consistent with the idea that on average, men have great attachment to the labor force, allocate more of their time to the market, and earn higher wages, and is consistent with the aggregate evidence we have presented. These factors imply higher annual earnings and hence a high probability of having Social Security benefits withheld due to earnings above the limit. Similarly, we find some evidence that conditions for withholding are more likely to be met among respondents with advanced degrees and among the financially knowledgeable individual in the household (columns 2, 3, and 4).

Based on the earnings criteria, individuals with higher public pension wealth, PIA, are more likely to experience benefit withholding. Again, the greater earnings power associated with these characteristics may translate into earnings above the limit. The fact that the PIA is associated with a lower chance of benefit decline (column 4) may be due to differences in withholdings after claiming. Individuals with high PIA who initiate benefits early may be relatively more likely to continue to work after claiming, resulting in the collection of initially lower benefits, and then withdraw for good before the NRA.

The results also show that having a private pension tends to be associated with a lower likelihood of withholding, potentially reflecting a post-claiming wealth effect on labor supply such that respondents with greater private pensions who work have shorter post-retirement working spells and pursue employment in non-career jobs that are lower-paying. Finally, having greater perceived longevity appears unrelated to benefit withholding, individuals with a health limitation for work are less likely to meet our benefit withholding criteria, which suggests that even among those who claim and continue to work, those in worse health have lower earnings power. 


\section{Evidence from a Life-Cycle Model}

\subsection{The usefulness of the Life-Cycle Approach for Policy Evaluation}

Before going into the details of the dynamic model we use to analyze the effects of policy reform to the Earnings Test provisions of the Social Security system, it is worth discussing why it is necessary to resort to the complexities of a full dynamic structural model to disentangle the effects at play. First, it is clear that the individuals who would be facing these new incentives are making intertemporal decisions under uncertainty, and are taking into account the existence and details of all social insurance programs for which they might be eligible. ${ }^{4}$ Second, given that the policy is new and has not been implemented on this population before, no other methodology is better equipped to assess the effects of this reform. Dynamic structural models provide a quasi-experimental setting in which we can keep constant the rest of the environment in order to isolate the effect of changes in incentives. However, this methodology comes with a cost; namely, that we need to make a host of assumptions in order to solve and simulate these kinds of models, where some of these assumptions are hard to justify except for tractability, and the need to set up the model with the objective of matching the data.

The best way to understand these models is to think about their different pieces, and how they come together to provide the policy recommendations that can help policy makers and lawmakers when making their decisions. Economic models can be described as having three connected pieces used to reflect the reality as close as possible. The first piece corresponds to the particular parameterization of preferences we will assume individuals have over consumption, leisure, health, or other variables considered to belong in the utility functions of individuals. Preferences also include a discount factor or a discount function that assesses the weight that future utility has with respect to current utility. Preference characterizations are ad-hoc, and the particular parameterizations hard to defend beyond their tractability and their mathematical properties that can sometimes be linked to certain behaviors which we believe reflect reality. In principle preferences could be

\footnotetext{
${ }^{4}$ See Benítez-Silva, Demiralp, and Liu (2008) for a recent discussion of what people know about Social Security rules in the United States using survey data, and the cost of their lack of knowledge of the details of the system.
} 
easily changed to match just about any observable behavior, leading to the debate over the lack of non-parametric identification of dynamic models (see Rust (1994), Taber (2000), and Magnac and Thesmar (2002)). This lack of identification is not very satisfying, which leads most researchers to use very similar characterizations of preferences using functions, the properties of which are well understood and studied, and then providing in some cases a study of how sensitive their results are to the particular preference assumptions. Researchers then claim identification of the model within the parametric family chosen, and hope to find the best model within the constraints of the chosen parametric model.

The second key element are the beliefs agents have about the future states of the world, and about how current states will evolve towards those states. Many models assume perfect foresight, such that uncertainty does not play any role, but the trend is towards allowing different sources of uncertainty in dynamic models, using empirical distributions and stochastic processes to reflect the likely beliefs of individuals over future states of the world. While researchers also have considerable freedom in how they set up this part of the model, in general empirical data constrain how they are characterized, and it is easier to check whether the characterization is appropriate for the problem at hand. Modeling health uncertainties, wage uncertainties, interest rate uncertainties, mortality uncertainties, unemployment uncertainties, uncertainties over future government policies, and so on, are becoming commonplace among researchers dealing with these types of models.

The third and final component, are the incentive structures set up to reflect the actual constraints faced by real decision makers. Theoretically this is simple: just take into account the constraints we know individuals face, and the laws specified in each case about the issue of study and include them in the model. However, in reality this can be quite complex since it requires keeping track of the large amount of information used by public and private entities to compute present and future benefits or future and present entitlements of all kinds. These complex incentive structures result in complications of the models and the need for simplifications in order to avoid the curse of dimensionality which results in the lack of tractability of many models that conceptually are 
simple but become too large very quickly.

The key of using dynamic models for the analysis of policy reforms is to isolate the effects of the changes to the incentive structure that individuals face, keeping their preference and beliefs constant. This provides useful and reliable results, assuming that the benchmark models provide a good characterization of reality. The results should in general be robust to different characterizations of preferences and beliefs, assuming those are such that they come close to replicating reality. Ideally, the benchmark models will be estimated and pass a rigorous test of the quality of their approximation to reality, but in many cases they are either too complex to estimate or data limitations prevents us from devising a full-fleshed estimation of the model, at least in the time frames required to provide timely policy recommendations.

We believe that economists should first put most of their efforts in characterizing as closely as possible to reality the incentive structure. After all, our social science is one of incentives, and it is the only piece connected with policy, since preferences are in general considered to be very hard (if at all possible) to change, and beliefs very slow to evolve and equally hard to modify through economic policy. While it is especially tempting (and many fall into that temptation rather easily) to use preference heterogeneity to explain behavior, it is less desirable than being able to account for it through the appropriate incentives, or even empirically grounded homogeneous beliefs about future events affecting economic constraints.

\subsection{A Dynamic Model of Retirement}

The model used in this paper is closely related to those presented in Rust and Phelan (1997), and Benítez-Silva, Buchinsky, and Rust (2003 and 2006). Rust and Phelan (1997) did not model consumption and savings decisions, but did estimate the parameters of the model, using a Nested Fixed-Point algorithm, instead of calibrating them. Benítez-Silva, Buchinsky, and Rust (2003 and 2006) present the most closely related models, which are calibrated to match aggregate data and household level data from the Health and Retirement Study, and model the Social Security Disability Insurance decisions on top of the OASI incentives. Unlike the structural model developed 
in the present paper, these earlier models (or any other structural models we are aware of) do not explicitly accounted for the possibility of affecting the Actuarial Reduction, or the possibility of expecting a possible benefit cut in the future. Our model also shares a number of characteristics with the work of French (2005), van der Klaauw and Wolpin (2005), and Blau (2008) among other researchers who solve, simulate, and in some cases estimate, dynamic retirement models under uncertainty.

We assume that individuals live a maximum of 100 years, and face mortality probabilities similar to those in the population. They start their working lives at age 21, and maximize the expected discounted stream of future utility, where the per period utility function $u(c, l, h, t)$ depends on consumption $c$, leisure $l$, health status $h$, and age $t$. We specify a utility function for which more consumption is better than less, with agents expressing a moderate level of risk aversion. The flip side of utility of leisure is the disutility of work. We assume that the utility (disutility of work) is an increasing function of age, is higher for individuals who are in worse health than individuals who are in good health, and is lower for individuals with higher human capital measured by the average wage. In addition, we assume that the worse an individual's health is, the lower their overall level of utility is, holding everything else constant. Moreover, we assume that individuals obtain utility from bequeathing wealth to heirs after they die. This model assumes that individuals are forward looking, and discount future periods at a constant rate $\beta$, assumed here to be equal to 0.96 .

The model also allows for a variety of sources of uncertainty, like lifetime uncertainty, health uncertainty, wage uncertainty, and more importantly, Social Security benefits level uncertainty. We will see in the next section that the latter is essential to match the large peak of benefits claiming at age 62. Notice, however, that within the model, this uncertainty is never realized, and benefits are never cut, but the existence of a small probability of the event happening affects behavior, and results in claiming benefits earlier, consistently with the empirical evidence.

Any person who is not already receiving Social Security Old Age benefits is eligible to apply for OASI benefits. ${ }^{5}$ Individuals with at least 40 quarters of earnings covered for OASI before

\footnotetext{
${ }^{5}$ We are abstracting from Social Security Disability Insurance (SSDI), a program that allows workers with severe disabilities to receive Social Security benefits before the NRA. This program currently covers about 7 million
} 
reaching their $62^{\text {nd }}$ birthday are eligible to apply and benefit award is guaranteed. In the present version of the model we allow decisions to be made on an annual basis and assume no lag between application date and date of first receipt.

Calculation of benefits and the reduction factors are as explained in the Appendix on incentives for early retirement, assuming a NRA of 66 . In particular the number of checks received in a year depends on the earnings after claiming: the number of checks (or the benefit amount on some checks received towards the end of the period) are reduced reflecting the $50 \%$ rate on labor incomes exceeding the Earnings Test limit between 62 and the January of the year a person turns 65 (33\% thereafter). In other words, adjustments to benefits and ARFs occurs in accordance with the earnings and the Earnings Test limit, and we do not consider the possibility that beneficiaries ask Social Security for a reduction of benefits or return benefits received. Even though we set up an annual decision-making process, the Social Security Earnings Test is enforced semiannually, i.e. the benefits received by a beneficiary are adjusted, after reaching the NRA, for the earnings in excess of the Earnings Test limit, as long as six months or more, of benefits were withheld in the years between the early and Normal Retirement Ages. The structure and the details of the model are described below.

\subsection{Model Details}

We solve the dynamic life-cycle model by backward induction, and by discretizing the space for the continuous state variables. ${ }^{6}$ The terminal age is 100 and the age when individuals are assumed to enter the labor force is 21 . Prior to their $62^{\text {nd }}$ birthday, agents in our model make a leisure and consumption decision in each period. At 62 and until age 70, individuals decide on leisure, consumption, and application for OASI benefits, denoted $\left\{l_{t}, c_{t}, s s d_{t}\right\}$, at the beginning of each period, where $l_{t}$ denotes leisure, $c_{t}$ denotes consumption, which is treated as a continuous decision variable, and $s s d_{t}$ denotes the individual's Social Security benefit claiming decisions.

Americans. See Benítez-Silva, Buchinsky, and Rust (2003 and 2006) for a life-cycle model of retirement and SSDI application.

${ }^{6}$ See Rust (1996), and Judd (1998) for a survey of numerical methods in economics. 
After age 70 is assumed that all individuals have claimed benefits, and again only consumption and leisure choices are possible. Leisure time is normalized to 1 , where $l_{t}=1$ is defined as not working at all, $l_{t}=.543$ corresponds to full time work, and $l_{t}=.817$ denotes part-time work. These quantities correspond to the amount of waking time spent non-working, assuming that a full-time job requires 2000 hours per year a part-time job requires 800 hours per year. We assume two possible values for $s s d_{t}$. If $s s d_{t}$ equals 1 the agent has initiated the receipt of benefits. If the individual has not filed for benefits or is not eligible then $s s d_{t}$ is equal to 0 .

If benefits are claimed before the NRA the monthly benefit amount is calculated similar to equation (1) in the Appendix. For a NRA of 66 years the reduction factor if claimed at 62 is $75 \%, 80.0 \%$ if claimed at $63,86.67 \%$ if claimed at 63 , and $93.33 \%$ if claimed at 65 . Due to the Earnings Test, benefit initiation between the ERA and the NRA does not necessarily imply benefit receipt, nor is the reduction in the benefit rate necessarily permanent after the NRA as a result of the adjustment of the ARFs as discussed in the Appendix (see equation (2)). In particular, we use an annual Earnings Test limit of \$12,480 between 62 and 65 and \$33,240 between 65 and 66 (these numbers reflect the 2006 limits). In the former period benefits are reduced at a rate of $\$ 1$ per $\$ 2$ of earnings above the limit and $\$ 1$ per $\$ 3$ of earnings above the limit for the latter period. These are the correct rules for someone who turns 66 in December. Since those whose birthday is earlier in the year face the higher limit and lower tax rate for less than a year (January to month of birthday) we have also simulated two alternative versions, one with the $\$ 12,480$ limit throughout, and another using $\$ 20,760$, the midpoint between the two limits and a tax rate of $50 \%$. The results of these models do not differ markedly from those presented in the paper and are available from the authors upon request. Those claiming after 66 earn the delayed retirement credit. We model it following the rates faced by the 1943-1954 cohorts, of 2/3 of 1\% for each month not claimed between age 66 and 70 .

We also incorporate a detailed model of taxation of other income, including the progressive federal income tax schedule (including the negative tax known as the EITC - Earned Income Tax Credit), and state and local income, sales and property taxes. Individuals whose combined income 
(including Social Security benefits) exceeds a given threshold must pay Federal income taxes on a portion of their Social Security benefits. We incorporate these rules in our model as well as the $15.75 \%$ Social Security payroll tax.

The model allows for three different sources of uncertainty: (a) lifetime uncertainty: modeled to match the Life Tables of the United States with age and health specific survival probabilities; (b) wage uncertainty: modeled to follow a log-normal distribution, function of average wages as explained in more detail below; (c) health uncertainty: assumed to evolve in a Markovian fashion using empirical transition probabilities from a variety of household surveys, including the NLSY79 and the HRS. The random draws to simulate these three sources of uncertainty are the same for all the models compared in this paper, such that the differences presented in the results are only due to the changes in the incentive schemes.

As explained in the previous section, we use reasonable parameter values based on aggregate data and household surveys. The state of an individual at any point during the life cycle can be summarized by five state variables: (i) Current age $t$; (ii) net (tangible) wealth $w_{t}$; (iii) the individual's Social Security benefit claiming state $s s_{t}$; (iv) the individual's health status, and (v) the individual's average wage, $a w_{t}{ }^{7}$ For computational simplicity, we assume that decisions are made annually rather than monthly, but we allow for the benefit adjustments due to earnings above the Earnings Test limit to happen semi-annually. This means that although individuals can only decide to claim benefits at the time they turn 62, 63, etc. their Social Security state can be updated every year, depending in their labor earnings, to reflect that their benefits will be adjusted for benefits withheld for periods of six months, or one year. Since the adjustment in benefits becomes effective only after they reach the NRA individuals still receive benefits at the original claiming rate in the period between the time of withholding of benefits until the NRA, consistent with current rules.

The $s s_{t}$ variable can assume up to fourteen mutually exclusive values between 62 and 66 :

\footnotetext{
${ }^{7}$ This translates into a problem with over half a million states in which to solve the model ( 80 periods, 15 discretized wealth states, 8 discretized average wage states, 3 health states, and 18 Social Security states). We are able to solve this model and simulate it 10,000 times in under 20 minutes in a Dual-Processor Linux Machine with 3.6GHz Xeon Processors using Gauss, and exploiting its capability to link dynamic libraries written in $\mathrm{C}$ by the authors and some of their co-authors. These $\mathrm{C}$ libraries perform over $95 \%$ of the computations involved in solving and simulating these models. The code used for these simulations is available upon request, and will eventually be available on the web.
} 
$s s_{t}=0$ (not entitled to benefits), $s s_{t}=62$ (entitled to OASI benefits at the ERA), and $s s_{t}=$ $62.5,63,63 n, 63.5,64,64 n, \ldots, 65.5,66,66 n$ represents the remaining 12 Social Security states corresponding to the level of benefits individuals will receive when they reach the NRA. For individuals who decide to claim after the NRA, $s s_{t}$ can take four additional values, age 67 to 70 , since everyone is assumed to claim no later than age 70. We created an additional (implicit state) variable, $s s n_{t}$, which can assume up to five mutually exclusive values: $s s n_{t}=0$ (all benefits received, i.e. no benefits withheld), $s s n_{t}=1$ (representing an original claim at age 62 of someone who had some benefits withheld; this applies, for example, to individuals with a $s s_{t}$ equal to $62.5,63 n$, or $64 n$ ), $s s n_{t}=2$ (representing an original claim at age 63 for someone who had some benefits withheld), $s s n_{t}=3$ (representing an original claim at age 64 for someone who had some benefits withheld), etc. With this structure we are able to separate, for example, whether someone is a 63 claimer, denoted by $s s_{t}=63$, or is really a 62 claimer who has accumulated one year of withheld benefits, represented here by $s s_{t}=63 n$. These two individuals will receive the same amount of benefits after the NRA, but their benefit would differ before the NRA, as explained in the Appendix, and in additional detail in Benítez-Silva and Heiland (2006, and 2007).

In addition to age, wealth, health, Social Security status, Benefit Adjustment status, and current income, the average indexed wage is a key variable in the dynamic model, serving two roles: (1) it acts as a measure of permanent income that serves as a convenient sufficient statistic for capturing serial correlation and predicting the evolution of annual wage earnings; and (2) it is key to accurately model the rules governing payment of the Social Security benefits. An individual's highest 35 years of earnings are averaged and the resulting Average Indexed Earnings (AIE) is denoted as $a w_{t}$. The PIA is the potential Social Security benefit rate for retiring at the NRA. It is a piece-wise linear, concave function of $a w_{t}$, whose value is denoted by pia $\left(a w_{t}\right)$.

In principle, one needs to keep as state variables the entire past earnings history. To avoid this, we follow Benítez-Silva, Buchinsky, and Rust (2006) and approximate the evolution of average wages in a Markovian fashion, i.e., period $t+1$ average wage, $a w_{t+1}$, is predicted using only age, $t$, current average wage, $a w_{t}$, and current period earnings, $y_{t}$. Within a log-normal regression 
model, we follow Benítez-Silva, Buchinsky, and Rust (2003), such that:

$$
\log \left(a w_{t+1}\right)=\gamma_{1}+\gamma_{2} \log \left(y_{t}\right)+\gamma_{3} \log \left(a w_{t}\right)+\gamma_{4} t+\gamma_{5} t^{2}+\varepsilon_{t}
$$

The $R^{2}$ for this type of regression is very high, with an extremely small estimated standard error, resulting from the low variability of the $\left\{a w_{t}\right\}$ sequences. This is a key aspect of the model given the important computational simplification that allows us to accurately model the Social Security rules in our DP model with minimal number of state variables.

We then use the observed sequence of average wages as regressors to estimate the following log-normal regression model of an individual's annual earnings:

$$
\log \left(y_{t+1}\right)=\alpha_{1}+\alpha_{2} \log \left(a w_{t}\right)+\alpha_{3} t+\alpha_{4} t^{2}+\eta_{t}
$$

This equation describes the evolution of earnings for full-time employment. Part-time workers are assumed to earn a pro-rata share of the full-time earnings level (i.e., part-time earnings are $0.8 \cdot 800 / 2000$ of the full-time wage level given in equation (5)). The factor of 0.8 incorporates the assumption that the rate of pay working part-time is $80 \%$ of the full-time rate. Using the history of earnings from the restricted HRS data set we obtained very high $R^{2}$ using this methodology.

The advantage of using $a w_{t}$ instead of the actual Average Indexed Earnings is that $a w_{t}$ becomes a sufficient statistic for the person's earnings history. Thus we need only keep track of $a w_{t}$, and update it recursively using the latest earnings according to (4), rather than having to keep track of the entire earnings history in order to determine the 35 highest earnings years, which the AIE requires.

For the 1943-1954 cohort the NRA is 66 and the PIA is permanently reduced after the NRA by an actuarial reduction factor of $\exp \left(-g_{1}(k-a d j m)\right)$, where $k$ is the number of years prior to the NRA but after the ERA that the individual first starts receiving OASI benefits and adjm corrects for periods where no benefits were received due to earnings above the Earnings test limit. Before the NRA, benefits are reduced by an actuarial reduction factor of $\exp \left(-g_{1} k\right)$. In the absence of 
adjustments to the ARFs, the actuarial reduction rate for the 1943 to 1954 cohort is $g_{1}=.0713$, which results in a reduced benefit of $75 \%$ of the PIA for an individual who first starts receiving OASI benefits at age 62 in the absence of any adjustments of the ARFs. In the policy simulations that increase the NRA to 67 , the reduced benefit at age 62 is $70 \%$ of the PIA.

To increase the incentives to delay retirement, the 1983 Social Security reforms gradually increased the NRA from 65 to 67 and increased the delayed retirement credit. This is a permanent increase in the PIA by a factor of $\exp \left\{g_{2} l\right\}$, where $l$ denotes the number of years after the NRA that the individual delays receiving OASI benefits. The rate $g_{2}$ is being gradually increased over time. The relevant value for the 1943 to 1954 cohort is $g_{2}=0.0769$, which corresponds to an increase in $8 \%$ in benefits per year of delay after the NRA. The maximum value of $l$ is MRA-NRA, where MRA denotes a "maximum retirement age" (currently 70), beyond which further delays in retirement yield no further increases in PIA. Clearly, it is not optimal to delay applying for OASI benefits beyond the MRA, because due to mortality, further delays generally reduce the present value of OASI benefits the person will collect over their remaining lifetime.

We assume that the individual's utility is given by

$$
u_{t}(c, l, h, a g e)=\frac{c^{\gamma}-1}{\gamma}+\phi(a g e, h, a w) \log (l)-2 h,
$$

where $h$ denotes the health status and $\phi(a g e, h, a w)$ is a weight that can be interpreted as the relative disutility of work. We use the same specification for $\phi$ and the disutility from working as in BenítezSilva, Buchinsky, and Rust (2006). The disutility of work increases with age, and is uniformly higher the worse one's health is. If an individual is in good health, the disutility of work increases much more gradually with age compared to the poor health, or disabled health, states. The disutility of work decreases with average wage. We postulate that high wage workers, especially highly educated professionals, have better working conditions than most lower wage blue collar workers, whose jobs are more likely to involve less pleasant, more repetitive, working conditions and a higher level of physical labor. 
We assume that there are no time or financial costs involved in applying for OASI benefits. The parameter $\gamma$ indexes the individual's level of risk aversion. As $\gamma \rightarrow 0$ the utility of consumption approaches $\log (c)$. We use $\gamma=-.37$, which corresponds to a moderate degree of risk aversion, i.e., implied behavior that is slightly more risk averse than that implied by logarithmic preferences.

Let $V_{t}(w, a w, s s, h)$ denote the individual's value function, the expected present discounted value of utility from age $t$ onward for an individual with current wealth $w$, average wage $a w$, in Social Security state ss and health state $h$. We solved the DP problem via numerical computation of the Bellman recursion for $V_{t}$ given by

$$
\begin{aligned}
& V_{t}(w, a w, s s, h)=\max \quad V_{t}(w, a w, s s, c, l, s s d, h), \quad \text { where } \\
& 0 \leq c \leq w \\
& l \in\{.54, .81,1\} \\
& s s d \in A_{t}(s s) \\
& V_{t}(w, a w, s s, c, l, s s d, h)=u_{t}(c, l, h)+\beta\left[1-d_{t}(h)\right] E V_{t+1}(w, a w, s s, c, l, s s d, h), \\
& +d_{t}(h) E B(w, a w, s s, c, l, s s d, h) \text {. }
\end{aligned}
$$

where $A_{t}(s s)$ denotes the set of feasible Social Security choices for a person of age $t$ in Social Security state $s s$ and $d_{t}(h)$ denotes the age and health-specific mortality rate, $B(w)$ is the bequest function, and $E B$ denotes its conditional expectation. We have used the HRS and AHEAD data to estimate age and health-specific death rates, but since there is little data on individuals over 80 years old we make parametric smoothness assumptions on the $d_{t}(h)$ function (basically a logit functional form that is polynomial in $t$ and has dummy variables for the various health states $h$ ) and subject the estimates to the further restriction that for each $t$ the expected hazard over $h$ should equal the unconditional age-specific death rates given in the 1997 edition of the U.S. Decennial life tables. ${ }^{8}$ The function $E V_{t+1}$ denotes the conditional expectation of next period's value function,

\footnotetext{
${ }^{8}$ De Nardi, French, and Jones (2006) find that more sophisticated mortality characterizations do not seem to significantly improve the fit of a related dynamic structural model which focuses on post-retirement saving behavior.
} 
given the individual's current state $(w, a w, s s, h)$ and decision $(c, l, s s d)$. Specifically, we have

$$
\begin{aligned}
E V_{t+1}(w, a w, s s, c, l, s s d, h)= & \int_{y^{\prime}} \sum_{h^{\prime}=0}^{2} \sum_{s s^{\prime}=0}^{17} V_{t+1}\left(w p_{t}\left(w, a w, y^{\prime}, s s, s s d\right), a w p_{t}\left(a w, y^{\prime}\right), s s^{\prime}\right) \\
& \times f_{t}\left(y^{\prime} \mid a w\right) k_{t}\left(h^{\prime} \mid h\right) g_{t}\left(s s^{\prime} \mid a w, w, s s, s s d\right) d y^{\prime},
\end{aligned}
$$

where $a w p_{t}(a w, y)$ is the Markovian updating rule that approximates Social Security's exact formula for updating an individual's average wage, and $w p_{t}$ summarizes the law of motion for next period's wealth, that is,

$$
w p_{t}(w, a w, y, s s, s s d)=R\left[w+s s b_{t}\left(a w, y^{\prime}, s s, s s d\right)+y^{\prime}-\tau\left(y^{\prime}, w\right)-c\right],
$$

where $R$ is the return on saving, and $\tau(y, w)$ is the tax function, which includes income taxes such as Federal income taxes and Social Security taxes and potentially other types of state/local income and property/wealth taxes. The $a w p_{t}$ function, derived from (4), is given by

$$
a w p_{t}(a w, y)=\exp \left\{\gamma_{1}+\gamma_{2} \log (y)+\gamma_{3} \log (a w)+\gamma_{4} t+\gamma_{5} t^{2}+\sigma^{2} / 2\right\}
$$

where $\sigma$ is the estimated standard error in the regression (4). Note there is a potential "Jensen's inequality" problem here due to the fact that we have substituted the conditional expectation of $w_{t+1}$ into the next period value function $V_{t+1}$ over $w_{t+1}$ and $a w_{t+1}$ jointly. However, as noted above, the $R^{2}$ for the regression of $a w_{t+1}$ on $a w_{t}$ is virtually 1 with an extremely small estimated standard error $\hat{\sigma}$. In this case there is virtually no error resulting from substituting what is an essentially deterministic mapping determining $a w_{t+1}$ from $w_{t+1}$ and $a w_{t}$.

Above, $f_{t}(y \mid a w)$ is a log-normal distribution of current earnings, given current age $t$ and average wealth $a w$, that is implied by (5) under the additional assumption of normality of errors $\eta_{t}$. The discrete conditional probability distributions $g_{t}\left(s s^{\prime} \mid a w, w, s s, s s d\right)$ and $k_{t}\left(h^{\prime} \mid h\right)$ reflect the transition probabilities in the Social Security and health states, respectively. 


\section{Simulation Results and Policy Experiments}

\subsection{Three Period Model}

To illustrate the main mechanisms and sources of uncertainty of the life cycle framework as they relate to benefit claiming, we will start the discussion with results from a three-period version of the model. Here, we think of the second period as the period of early retirement, roughly corresponding to age 62. Individuals retire (draw benefits for sure) in the third (last) period, corresponding to age 70 . In the benchmark calibration of this model, we assume that benefits received in period two are subject to an adjustment factor of $46.66 \%$, i.e. the penalty for claiming benefits early is 53.34\%. Abstracting from the Delayed Retirement Credit and the Earnings Test which cannot be meaningfully represented in the three period version of the model, this penalty for early benefits can be illustrated as the product of 96 months, the number of months between 62 and 70, and 5/9 of $1 \%$, the current actuarial reduction for every month between the ERA and the year in which the individual reaches the NRA.

The benchmark model with a reduction factor of $46.66 \%$, a $20 \%$ mortality rate, and a discount factor, $\beta$, of 0.96 predicts about equal fractions of early vs. late claiming. Based on 10,000 simulations, the percentage of individuals claiming early (period two) is 50.95\%, with the remaining $49.05 \%$ of individuals drawing up benefits in period three. Raising the adjustment factor lowers the penalty associated with claiming benefits early, causing a greater fraction of individuals to choose to claim benefits early, all else equal. For example, increasing the adjustment factor from $46.66 \%$ as in the benchmark model to $55 \%$, results in $62.13 \%$ of individuals claiming benefits early. ${ }^{9}$

Life expectancy is an important source of uncertainty affecting the distribution of benefit claiming: An increase in the period mortality risk from $20 \%$ (baseline) to $25 \%$ results in $58.2 \%$ of in-

\footnotetext{
${ }^{9}$ This exercise can also be understood in the context of the discussion of Queisser and Whitehouse (2006), who using 2002 mortality data, find that the US reduction for early retirement is not actuarially fair (it is too low), and too generous given current mortality figures, which results in a subsidy of early retirement and a penalization of late retirement. The case of the lower penalty represents what (the now longer lived) individuals are actually facing, while the benchmark shows what they should be facing if the system was actuarially fair in line with newer mortality data. Our result clearly shows that the case with a lower penalty leads to more early claiming. This can in part explain the preference for early retirement expressed by Americans in the last decades.
} 
dividuals claiming benefits early. ${ }^{10}$ Intuitively, a greater mortality risk induces a decline in the expected level of satisfaction from future consumption and leisure (which is now less likely to occur), causing a shift towards more consumption in earlier periods. As discussed above, health uncertainty is linked to early claiming as a worse health condition makes working more difficult (it increases the disutility from work). In the benchmark model we assume an initial health distribution and a subsequent deterioration of health according to empirically based health transition rates. Ignoring health transitions leads to more individuals surviving and a more healthy population in period two and three. The percentage of individuals claiming benefits early is reduced to $40.9 \%$, consistent with more labor supply and less reliance on (reduced) public pension benefits in period two.

We also considered a number of other variations that help us understand the mechanisms at play in this type of model. First, we changed the discount factor to model different degrees of impatience among individuals. When lowering the discount factor from the benchmark level of 0.96 to 0.90 , the share of individuals who claim early rises from $50.95 \%$ to $53.64 \%$. We also obtained predictions for claiming behavior in models assuming a $20 \%$ higher initial wealth level and a $20 \%$ higher initial average wage, respectively, compared to the benchmark case. A greater initial wealth is associated with more early claiming, from the $50.95 \%$ of the benchmark to $55 \%$, consistent with an increase in the demand for leisure (wealth effect), especially in periods two and three. Similarly, a rise in the initial wage distribution induces a net increase in early claiming as well due to the higher life time income; $53.15 \%$ of individuals claim in period two in this case.

While the net effect of an increase in initial wealth and average wage is rather similar on the benefits claiming decision, the effect on labor supply is quite different. The higher initial wealth leads to lower labor force participation in the three periods, and especially in period three. On the other hand, the higher initial average wage leads to higher labor force participation in periods one and three, and almost identical participation in period two. Furthermore, the percentage of full-time workers goes up sharply in periods two and three. In the case of the shift in the initial

\footnotetext{
${ }^{10}$ The baseline mortality probabilities were chosen such that the number of individuals in the simulations who survive to period two and three roughly matches the number of survivors to age 62 and 70 in the full model.
} 
wage distribution, the induced (negative) wealth effect on leisure is offset for some individuals by a substitution effect resulting from higher period wages. The latter effect is reinforced by the characterization of the disutility of work which is sensitive to changes in the average wage as discussed above.

\subsection{Main Results}

Tables 1 to 4 provide the information on the proportion of individuals claiming benefits at different ages since 1994, as well as their benefits levels, using the aggregate information provided in the Statistical Supplement to the Social Security Bulletin (for the period between 1994 and 2006), as well as from the OASDI Public-Use Microdata File in its 2004 release. These two sources of data are intimately related since they come from the same Master Beneficiary Record of all Americans that contribute to the Social Security system, but they present information in a slightly different way, complementing each other in very interesting ways.

In particular, the information we use from the Supplement is reported in Table 6.A4 of the 2007 edition, and in similar tables in the historical editions of the document. The table in question reports the exact number of Americans claiming retirement benefits at each age in a given year, and also the average benefit level for those claiming at a particular age in that particular year. Notice that a given individual only appears in one of the cells identified by age and year, and that corresponds to the first time they apply for benefits. We present this data in Tables 1 and 2 below.

The 2004 Benefits and Earnings Public-Use File is a one-percent random sample of OASDI beneficiaries who were on the Social Security records in December 2004. It contains 473,366 records as of December 2004, and includes information in sixteen fields on OASDI beneficiaries' characteristics, mainly about benefits entitlements. This more detailed information allows us to focus only on retired workers who claimed on their own earnings history

Overall, the main difference between the two sources of data is that the Microdata, since it only includes individuals who claim on their own earnings history, is a better comparison to our model. As we will see below, this is good news for us, since the proportions of individuals claiming at the 
different ages matches very well with the predictions of our preferred model. ${ }^{11}$

Table reports results from two different models of Social Security, assuming a NRA of $66 .{ }^{12}$ Model 1 treats the Earnings Test as a pure tax on earnings above the corresponding ET limit, which is how it may be perceived by a proportion of the general public given the difficulties in understanding the role of the adjustment factors when working beyond benefit take-up (Benítez-Silva and Heiland, 2007 and 2008), and how a majority of researchers have modeled these incentives. Using this framework, our model of optimal behavior predicts that only about $25 \%$ of claimers would take up at age 62 , with a larger peak at 65 at roughly $32 \%$, with a bulk of the remaining beneficiaries claiming at the ages in between. Benefits, given this behavior, increase slightly with age at all points so that there are economic incentives for delaying take-up.

With the implementation of the proper Earnings Test incentives, which allow for the modification of the actuarial reduction factor through work after take-up with earnings above the ET limit, Model 2 shows a trend towards earlier claiming of benefits. This moves us closer to the actual take-up rates with a jump from only $25 \%$ claiming at 62 in Model 1 to over $48 \%$ in Model 2. The actual current take-up rate is around 53.8\% if we use SSA's Statistical Supplement, 2007, but $49.6 \%$ as of 2004 if we use the more reliable Public-Use Microdata File, as explained above, which only focuses on the retirement behavior of workers and does not include the dependents as the Statistical Supplement. There continues to be a second peak at age 65, this time smaller, with $23.66 \%$ of the sample (in the Public-Use Microdata File is $20 \%$ ), and around $4 \%$ waiting to age 66.

The results of Model 2 (which we label the benchmark model) also provide evidence that our model does a good overall job in matching the resources that individuals have, since the benefits levels predicted by the model are of the same order of magnitude as those in the data, eventhough the model predicts higher benefits. Given that we are using a NRA of 66, and individuals also

\footnotetext{
${ }^{11}$ See Benítez-Silva and Yin (2008) for a detailed analyzes of these sources of data and how they can be used to analyze the effects of recent changes to the Social Security System.

${ }^{12}$ In this paper we focus on claiming behavior and labor supply, but the model also simulates the evolution of wealth, consumption, and wages over the life cycle. As shown in Benítez-Silva, Buchinksy, and Rust (2006), in a related model, the predictions of the model are consistent with the HRS data.
} 
face the Earnings Test between age 65 and 66 as a result, the relationship between benefit levels at different ages is closer to that present in the period before the elimination of the ET for those above the NRA. This translates in the prediction that later claimers obtain higher benefits.

More importantly for the purposes of our study of benefits withholding we can see that the model predicts a proportion of individuals facing benefits withholding of around $9.7 \%$ at age 62 , around $8 \%$ at age 63 , and $5 \%$ at age 64 . This is reported in the column labeled ARFs, which gives the count of individuals with some checks withheld. These numbers although a bit higher than the currently prevailing proportions, are not very different from the numbers observed just a few years ago. From the last column of the table we can see that individuals who earn in a given year above the ET limit earn well above that limit. These results are in sharp contrast from Model 1, which predicts a much lower numbers of individuals earning above the limit between ages 62 and 64, and even among those who have withholdings their earnings are much lower than in Model 2.

The overall performance of the benchmark model gives us confidence in using the model to perform some policy experiments regarding the structure of the Earnings Test.

\subsection{Policy Experiments}

Table simulates behavioral responses to changes in the provisions of the Earnings Test in the Social Security Retirement system. We solve and simulate three models: one in which the Earnings Test limit is increased for those between 62 and 65 to the same level prevalent for those between 65 and the NRA; a second one in which the taxation of earnings above the limit decreases from $50 \%$ to $33 \%$ for those between age 62 and 65 ; and finally we also analyze the consequences of removing the Earnings Test altogether.

The first panel of Table shows the consequences of increases the Earnings Test limit for those between age 62 and 65 to the same level as for those between age 65 and the NRA, which means above $\$ 33,240$. The policy has a clear effect on claiming behavior, with more individuals claiming early, in fact around 56\% would claim at age 62. The change also leads to a slight decrease in fulltime work between age 62 and 64, with a corresponding increase in part-time work. The number 
of individuals affected by the ET goes down considerably compared with the benchmark model, but among those affected the earnings levels are much higher than before.

The second panel of this table shows the effects of changing the tax rate on benefits when individuals earn above the limit between ages 62 and 65 . When we change the rate from the current $50 \%$ to $33 \%$, the claiming behavior is only slightly affected compared with the benchmark model, but in clear contrast to the results in panel one above. In this case the proportions of those claiming at age 62 goes down slightly. Additionally, labor supply also has a very small response to this change, with only minor changes in the distribution of individuals choosing to work fulltime, part-time, or not working. Notice as well, that the proportions of those facing adjustment in benefits due to withholding goes down but not as much as under the previous experiment. The drop in those affected is to be expected since now the tax rate is lower.

Finally, panel three in this table shows the experiment of removing the Earnings Test altogether. The claiming behavior changes dramatically with respect to the benchmark model, and over 64\% of individuals claim at age 62, with smaller proportions claiming at the other ages. The largest effect is in labor supply for those age 62 and 63. At both ages we see a drop in full-time work, with a large increase in part-time work at age 63, which is still present at age 64. Interestingly, among those who work, their realized wages result in more of them being above the now revoked earnings test limit. All this evidence suggests the presence of two effects, one pushing towards early claiming and early retirement resulting in the lower participation at age 62, and one pushing towards more work resulting in the higher participation at all other ages. These results are in line with our findings in Benítez-Silva and Heiland (2007), and the discussion therein.

The results from this policy analysis suggest that only a removal of the Earnings Test is likely to have sizable consequences on labor supply and earnings of individuals, while tinkering with the details of the ET provision will likely have small effects on behavior and outcomes. 


\section{Conclusions}

Since the removal of the Earnings Test in the year 2000 for those above the NRA, there has been relatively little discussion of the Earnings Test for younger retirees, despite the fact that as the NRA increases a larger proportion of Americans will be affected by it. In order to adopt any reform the research community and policy makers must understand how individuals respond to these incentives that affect the interaction between work, retirement benefits, and retirement behavior. This paper provides better documentation and understanding of individuals' monthly benefit receipt and withholding, and we expect it will provide researchers and policy makers with a level of detail that facilitates, among other things, more accurate predictions of life cycle benefit outlays across demographics as the NRA increases. Also important for policy, our work identifies some of the characteristics of those that are less likely to experience benefit withholding, for example they are more likely to be females, be less educated, have access to private pensions, and have a health limitation for work. These findings will help provide a quantitative measure of the possible induced entry effect into the SSDI or SSI program if the Early Retirement Age were to be increased. We believe the interaction between retirement and disability benefits is likely to be significantly affected by the work incentives provided by the Earnings Test.

As the population ages, and the number of years between the Early and the Normal Retirement Age increases over time, the administrative costs and the welfare burden currently associated with the Earnings Test and the actuarial reduction mechanism will likely increase since these incentives affect every American who reaches retirement age. As part of the ongoing debate on Social Security Reform, one possible set of changes that has been discussed includes increasing both the NRA and the ERA in the coming years in order to avoid even more radical changes to the system. Although raising the early retirement age appears to have little support today, it cannot be ruled out that it will be considered more seriously as the system approaches insolvency. If the limited documentation of the Earnings Test and its role in affecting the rate of future benefits remains, its distortionary incentives are likely to continue to affect millions of Americans who consider working after claiming benefits early. As the NRA increases, the distortions will increasingly affect 
older retirees, and if the ERA also increases, the burden shifts from younger to older retirees.

Using a fairly realistic dynamic model of retirement, we find that neither fairly important changes in some of the provisions of the Earnings Test, nor the elimination of the ET might have a large enough effect on labor supply and earnings to meaningfully address the solvency problems of the system, and could in fact lead to even earlier claiming in the case of an increase in the Earnings Test limits or its elimination. ${ }^{13}$ Therefore, in the hope of improving the solvency of the system, alternatives policies should be analyzed. The possibility of increasing the Early Retirement Age would mechanically delay claiming benefits and likely increase labor supply in the years leading to the new ERA, but would have a limited effect on the long run solvency of the system. Furthermore, it is highly regressive given the socio-demographic composition of early claimers. An alternative to those policies is to devise an actuarially unfair incentive structure in which late claiming is rewarded via higher benefits. The latter would be implemented hoping that the actual labor supply responses, and the resulting tax revenues, compensate for the cost of such a policy. While it is regressive, it might be less so than just increasing the Early Retirement Age.

\footnotetext{
${ }^{13}$ See Benítez-Silva and Heiland (2007), Song and Manchester (2007), French (2005), Song (2004), Gustman and Steinmeier (2004), Gruber and Orszag (2003), and Disney and Smith (2001) for a discussion of the labor supply effects of the removal of the Earnings Test.
} 


\section{References}

Auerbach, A., and K. Hassett (2006): "Optimal long-run fiscal policy: Constraints, preferences and the resolution of Uncertainty," Journal of Economic Dynamics and Control, 5 1-22.

Baker, M., and D. Benjamin (1999): "How do retirement tests affect the labour supply of older men?" Journal of Public Economics, $7127-51$.

Benítez-Silva, H., and F. Heiland (2008): "Early Claiming of Social Security Benefits and Labor Supply Behavior of Older Americans," forthcoming in Applied Economics.

Benítez-Silva, H., and F. Heiland (2007): “The Social Security Earnings Test and Work Incentives," Journal of Policy Analysis and Management, 26-3 527-555.

Benítez-Silva, H., M. Buchinsky, and J. Rust (2003): "Dynamic Structural Models of Retirement and Disability," manuscript, SUNY-Stony Brook, UCLA, and University of Maryland.

Benítez-Silva, H., M. Buchinsky, and J. Rust (2006): "Induced Entry Effects of a \$1 for \$2 Offset in SSDI Benefits," manuscript, SUNY-Stony Brook, UCLA, and University of Maryland.

Benítez-Silva, H., and N. Yin (2008): "An Analysis of the Effects of Recent Social Security Reforms Using Aggregate and Public-Use Administrative Micro Data," manuscript, SUNYStony Brook and CUNY-Baruch College.

Benítez-Silva, H., D.S. Dwyer, F. Heiland, and W.C. Sanderson (2008): "Retirement and Social Security Reform Expectations: A Solution to the New Early Retirement Puzzle," manuscript, SUNY-Stony Brook and Florida State University.

Benítez-Silva, H., Demiralp, B., and Liu, Z. (2008): "Knowledge, Information, and Costs," manuscript, SUNY-Stony Brook, Old Dominion University, and SUNY-Buffalo.

Blau, D. (2008): "Retirement and Consumption in a Life Cycle Model," Journal of Labor Economics, 26-1, 35-71.

Brown, R.L. (1996): "Social Security and Retirees: Two Views of the Projections, An Actuary's Perspective," in Social Security: What Role for the Future? P.A. Diamond, D.C. Lindeman, and H. Young (eds.) National Academy of Social Insurance. Washington, D.C.

Burtless, G., and R. A. Moffitt (1985): "The Joint Choice of Retirement Age and Post-Retirement Hours of Work," Journal of Labor Economics, 3 209-236.

Bütler, M. (1999): “Anticipation effects of looming public pension-reforms.” Carnegie-Rochester Conference Series on Public Policy, 50 119-159.

Coile, C., P. Diamond, J. Gruber, and A. Jousten (2002): "Delays in Claiming Social Security Benefits," Journal of Public Economics, 84-3 357-385

De Nardi, Mariacristina, E. French, and J.B. Jones (2006): "Differential Mortality, Uncertain Medical Expenses, and the Saving of Elderly Singles," manuscript. 
Disney, R. and S. Smith (2001): "The labour supply effect of the abolition of the earnings rule for older workers in the United Kingdom," Economic Journal, 112 C136-C152.

French, E. (2005): "The Effects of Health, Wealth, an Wages on Labour Supply and Retirement Behaviour," Review of Economic Studies, 72 395-427.

Friedberg, L. (1998): “The Social Security Earnings Test and Labor Supply of Older Men,” in Tax Policy and The Economy, Vol. 12. MIT Press.

Friedberg, L. (2000): “The Labor Supply Effects of the Social Security Earnings Test," Review of Economics and Statistics, 82 48-63.

Gruber, J., and P. Orszag (2003): "Does the Social Security Earnings Test Affect Labor Supply and Benefits Receipt?" National Tax Journal, 56(4) 755-773.

Gustman, A. L., and T. L. Steinmeier (1985): "Social Security Reform and Labor Supply,” NBER Working Paper No. 1212.

Gustman, A. L., \& Steinmeier, T.L. (1991): “Changing the Social Security Rules for Work after 65," Industrial and Labor Relations Review, 44 733-745.

Gustman, A. L., and T. L. Steinmeier (2002): “The Social Security Early Entitlement Age in a Structural Model of Retirement and Wealth,” NBER Working Paper No. 9183.

Gustman, A. L., and T. L. Steinmeier (2004): “The Social Security Retirement Earnings Test, Retirement and Benefit Claiming," Michigan Retirement Research Center No. 2004-090.

Haider, S., and G. Solon (2000): "Nonrandom selection in the HRS Social Security earnings sample," RAND Working Paper No. 00-01.

Honig, M., and C. Reimers (1989): "Is It Worth Eliminating the Retirement Test?" American Economic Review, 79 103-107.

Hurd, M. (1990): "Research on the Elderly: Economic Status, Retirement, and Consumption and Saving," Journal of Economic Literature, 28 565-637.

Judd, K.L. (1998): Numerical Methods in Economics, The MIT Press.

Leonesio, M. V. (1990): "Effects of the Social Security Earnings Test on the Labor Market Activity of Older Americans: A Review of the Evidence," Social Security Bulletin, 53 2-21.

Lumsdaine, R. (1995): "Factors Affecting Labor Supply Decisions and Retirement Income," NBER Working Paper No. 5223.

Lumsdaine, R., and O. Mitchell (1999): "New Developments in the Economic Analysis of Retirement," in Ashenfelter, O., Card, D. (Eds.), Handbook of Labor Economics, Vol. 3C. 3261-3307.

Magnac, T. and D. Thesmar (2002): “Identifying Dynamic Discrete Decision Processes,” Econometrica, 70-2 801-816. 
Mastrobuoni, G. (2006): "Do better-informed workers make better retirement choices? A test based on the Social Security Statement," manuscript, Princeton University.

Myers, R.J. (1993): Social Security. Fourth Edition. Pension Research Council and University of Pennsylvania Press.

Queisser, M, and E. Whitehouse (2006): "Neutral or Fair? Actuarial Concepts and PensionSystem Design.” OECD Social Employment, and Migration Working Papers, No. 40.

Reimers, C., and M. Honig (1993): “The Perceived Budget Constraint under Social Security: Evidence from Reentry Behavior,” Journal of Labor Economics, 11 184-204.

Reimers, C., and M. Honig (1996): "Responses to Social Security by Men and Women: Myopic and Far-Sighted Behavior,” Journal of Human Resources, 31-2 359-382.

Rejda, G. E. (1999): Social Insurance and Economic Security. Sixth Edition. Prentice Hall, New Jersey.

Ruhm, C. J. (1996): "Historical Trends and the Future of Older Americans," in Crown, W.H. (Ed.), The Handbook on Employment and the Elderly, Greenwood.

Rust, J. (1994): "Structural Estimation of Markov Decision Processes," in R. Engle and D. McFadden (eds.) Handbook of Econometrics, Vol. 4, 3082-3139, North Holland.

Rust, J. (1996): "Numerical Dynamic Programming in Economics," in Handbook of Computational Economics. H. Amman et al. (eds.). Amsterdam: Elsevier.

Rust, J., and C. Phelan (1997): "How Social Security and Medicare Affect Retirement Behavior in a World of Incomplete Markets," Econometrica, 65 781-831.

Sabelhauss, J., and J. Topoleski (2007): "Uncertain Policy for an Uncertain World: The Case of Social Security," Journal of Policy Analysis and Management, 26-3 507-525.

Song, J.G. (2004): "Evaluating the Initial Impact of Eliminating the Retirement Earnings Test," Social Security Bulletin, 65-1 1-15.

Song, J.G., and J. Manchester (2007): "New evidence on earnings and benefit claims following changes in the retirement earnings test in 2000," Journal of Public Economics, 91(3-4), 669700 .

SSA-S (various years): Annual Statistical Supplement to the Social Security Bulletin. http://www.ssa.gov/policy/docs/statcomps/supplement/.

SSA-H: Social Security Handbook. Online Version. http://www.ssa.gov/OP_Home/handbook/ssa-hbk.htm.

SSA-M: Program Operations Manual System (POMS). Public Version. https://s044a90.ssa.gov/apps10/poms.nsf/aboutpoms. 
SSA (2007): Annual Report of the Board of Trustees of the Federal Old-Age and Survivors Insurance and Federal Disability Insurance Trust Funds. Washington, D.C.

Taber, C.R. (2000): "Semiparametric Identification and Heterogeneity in Discrete Choice Dynamic Programming Models," Journal of Econometrics, 96 201-229.

Votruba, M. E. (2003): "Social Security And Retirees’ Decision to Work," manuscript, Case Western Reserve University.

Vroman, W. (1985): "Some Economic Effects of the Retirement Test," in Research in Labor Economics, Vol. 7. JAI Press.

van der Klaauw, W., and K.I. Wolpin (2005): "Social Security, Pensions and the Savings and Retirement Behavior of Households," manuscript. University of North Carolina-Chapel Hill. 
Figure 1: Early Claiming and Benefit Withholding. Master Beneficiary Data.
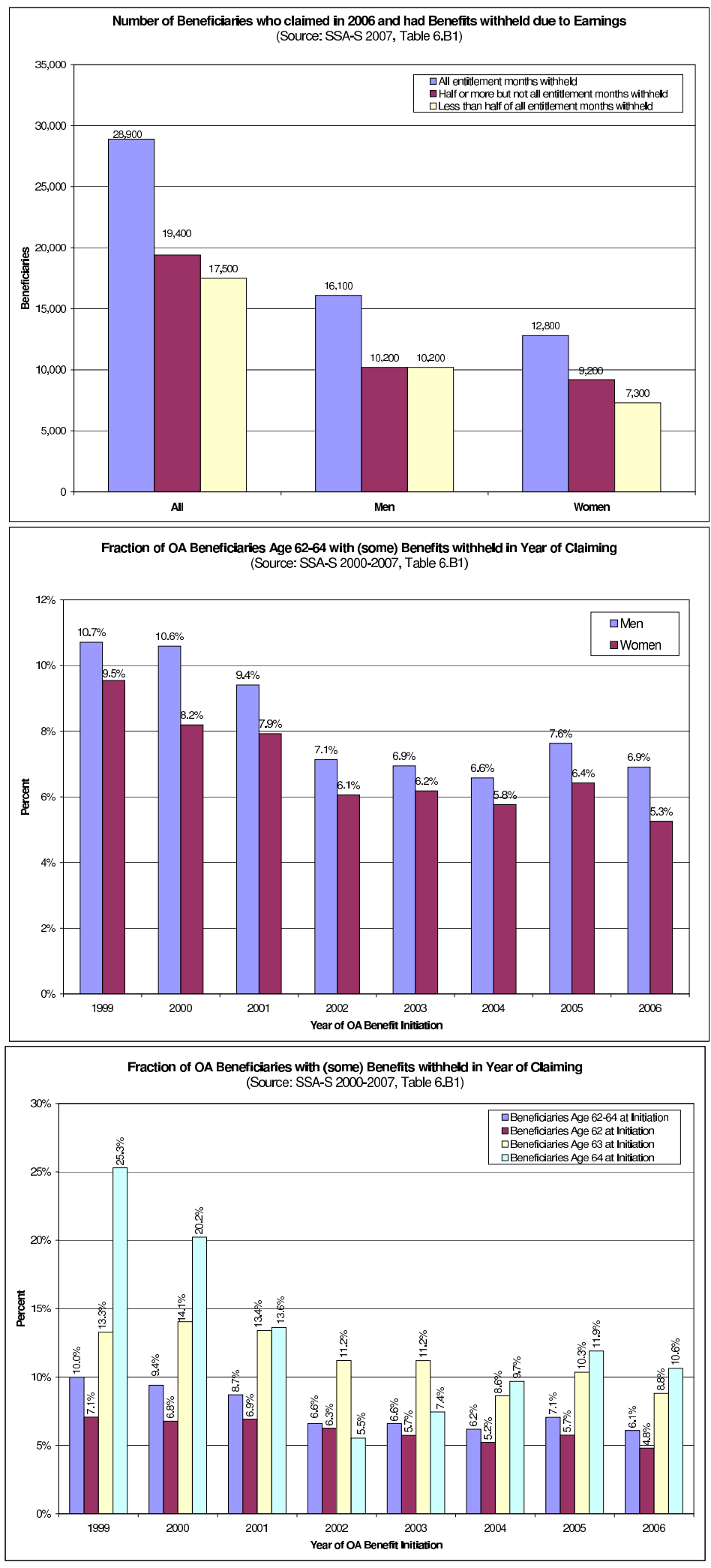
Table 1: Social Security Claiming Behavior, 1994-2006. Proportions by age of first receipt. Statistical Supplement.

\begin{tabular}{|c|c|c|c|c|c|c|c|c|c|c|c|c|c|}
\hline Age/Year & 1994 & 1995 & 1996 & $1997^{a}$ & $1998^{a}$ & 1999 & 2000 & 2001 & 2002 & 2003 & 2004 & 2005 & 2006 \\
\hline Age 62 & 0.589 & 0.582 & 0.60 & 0.597 & 0.583 & 0.586 & 0.517 & 0.554 & 0.56 & 0.569 & 0.575 & 0.566 & 0.538 \\
\hline Age 63 & 0.079 & 0.079 & 0.075 & 0.073 & 0.080 & 0.079 & 0.067 & 0.078 & 0.078 & 0.078 & 0.081 & 0.083 & 0.085 \\
\hline Age 64 & 0.121 & 0.116 & 0.108 & 0.105 & 0.107 & 0.107 & 0.104 & 0.134 & 0.148 & 0.127 & 0.109 & 0.099 & 0.104 \\
\hline Age 65 & 0.156 & 0.163 & 0.157 & 0.155 & 0.156 & 0.156 & 0.196 & 0.178 & 0.172 & 0.178 & 0.186 & 0.197 & 0.223 \\
\hline Age 66 & 0.018 & 0.018 & 0.019 & 0.021 & 0.021 & 0.019 & 0.039 & 0.013 & 0.009 & 0.010 & 0.012 & 0.014 & 0.011 \\
\hline Age 67-69 & 0.023 & 0.024 & 0.026 & 0.034 & 0.029 & 0.091 & 0.055 & 0.019 & 0.015 & 0.016 & 0.018 & 0.018 & 0.017 \\
\hline Age $70+$ & 0.019 & 0.017 & 0.014 & 0.015 & 0.023 & 0.022 & 0.021 & 0.022 & 0.016 & 0.019 & 0.018 & 0.020 & 0.022 \\
\hline \# of Claimants ${ }^{b}$ & 1,444 & 1,424 & 1,396 & 1,418 & 1,441 & 1,484 & 1,758 & 1,574 & 1,595 & 1,593 & 1,680 & 1,793 & 1,771 \\
\hline
\end{tabular}

Notes: ${ }^{a}$ The percentages do not coincide with those reported in the Statistical Supplements since we have not counted the 120,000 widows who were converted in these years from widow benefits to retirement benefits. ${ }^{b}$ In thousands of claimers. Does not include disability conversions at the NRA. 
Table 2: Social Security Beneficiaries' Monthly Benefits by Age, 1994-2006. In Dollars of 2005. Statistical Supplement.

\begin{tabular}{|c|c|c|c|c|c|c|c|c|c|c|c|c|c|}
\hline Age/Year & 1994 & 1995 & 1996 & 1997 & 1998 & 1999 & 2000 & 2001 & 2002 & 2003 & 2004 & 2005 & 2006 \\
\hline Age 62 & 789 & 789 & 785 & 802 & 815 & 856 & 865 & 884 & 893 & 900 & 888 & 882 & 878 \\
\hline Age 63 & 882 & 906 & 943 & 882 & 908 & 929 & 961 & 974 & 1,003 & 1,006 & 997 & 987 & 1,009 \\
\hline Age 64 & 982 & 983 & 997 & 1,015 & 1,002 & 988 & 1,020 & 1,073 & 1,120 & 1,120 & 1,102 & 1,089 & 1,088 \\
\hline Age 65 & 1,084 & 1,091 & 1,088 & 1,117 & 1,088 & 1,100 & 1,184 & 1,176 & 1,239 & 1,257 & 1,271 & 1,298 & 1,335 \\
\hline Age 66 & 1,022 & 1,077 & 1,033 & 1,049 & 1,030 & 1,094 & 1,248 & 940 & 882 & 920 & 981 & 1,052 & 1,087 \\
\hline Age 67 & 1,028 & 1,138 & 1,071 & 989 & 1,050 & 1,129 & 1,286 & 911 & 873 & 878 & 934 & 1,010 & 1,012 \\
\hline
\end{tabular}


Table 3: Social Security Claiming, 1994-2004. Proportions by Age of First Receipt. Public-Use Microdata.

\begin{tabular}{lccccccccccc}
\hline Age/Year & $\mathbf{1 9 9 4}$ & $\mathbf{1 9 9 5}$ & $\mathbf{1 9 9 6}$ & $\mathbf{1 9 9 7}^{a}$ & $\mathbf{1 9 9 8}^{a}$ & $\mathbf{1 9 9 9}$ & $\mathbf{2 0 0 0}$ & $\mathbf{2 0 0 1}$ & $\mathbf{2 0 0 2}$ & $\mathbf{2 0 0 3}$ & $\mathbf{2 0 0 4}$ \\
\hline Age 62 & 0.523 & 0.512 & 0.511 & 0.518 & 0.518 & 0.503 & 0.452 & 0.49 & 0.483 & 0.487 & 0.496 \\
Age 63 & 0.161 & 0.166 & 0.143 & 0.151 & 0.152 & 0.147 & 0.136 & 0.157 & 0.156 & 0.145 & 0.143 \\
Age 64 & 0.074 & 0.069 & 0.064 & 0.063 & 0.068 & 0.067 & 0.06 & 0.069 & 0.07 & 0.069 & 0.067 \\
Age 65 & 0.184 & 0.196 & 0.176 & 0.186 & 0.186 & 0.196 & 0.228 & 0.241 & 0.247 & 0.254 & 0.201 \\
Age 66 & 0.018 & 0.02 & 0.023 & 0.021 & 0.021 & 0.027 & 0.043 & 0.009 & 0.011 & 0.011 & 0.071 \\
Age 67-69 & 0.024 & 0.023 & 0.032 & 0.029 & 0.03 & 0.036 & 0.057 & 0.016 & 0.014 & 0.015 & 0.01 \\
Age 70+ & 0.016 & 0.014 & 0.05 & 0.032 & 0.025 & 0.024 & 0.024 & 0.018 & 0.019 & 0.019 & 0.012 \\
\hline \# of Claimants & 10,700 & 11,026 & 11,676 & 11,619 & 12,055 & 13,048 & 14,976 & 13,606 & 13,708 & 14,098 & 14,852 \\
\hline
\end{tabular}

Notes: ${ }^{a}$ This data is retired workers only. In the data, there is no way to separate disability converters from OA claimants at age 65 . What we have done is to assume a proportion of SS claimants from age-65 samples each year as disability converters. The proportions used are calculated according to the Annual Statistical Supplemental. 
Table 4: Social Security Beneficiaries' Monthly Benefits by Age, 1994-2004. In Dollars of 2005. Public-Use Microdata.

\begin{tabular}{lccccccccccc}
\hline Age/Year & $\mathbf{1 9 9 4}$ & $\mathbf{1 9 9 5}$ & $\mathbf{1 9 9 6}$ & $\mathbf{1 9 9 7}$ & $\mathbf{1 9 9 8}$ & $\mathbf{1 9 9 9}$ & $\mathbf{2 0 0 0}$ & $\mathbf{2 0 0 1}$ & $\mathbf{2 0 0 2}$ & $\mathbf{2 0 0 3}$ & $\mathbf{2 0 0 4}$ \\
\hline Age 62 & 853 & 831 & 834 & 840 & 849 & 890 & 879 & 891 & 909 & 906 & 860 \\
Age 63 & 903 & 928 & 906 & 905 & 918 & 917 & 958 & 945 & 948 & 964 & 913 \\
Age 64 & 1,016 & 1,015 & 1,021 & 989 & 985 & 1,016 & 1,027 & 1,085 & 1,094 & 1,080 & 1,064 \\
Age 65 & 1,138 & 1,129 & 1,128 & 1,134 & 1,103 & 1,103 & 1,123 & 1,151 & 1,194 & 1,197 & 1,146 \\
Age 66 & 1,238 & 1,129 & 1,188 & 1,145 & 1,204 & 1,225 & 1,292 & 945 & 914 & 1,041 & 1,196 \\
Age 67 & 1,157 & 1,170 & 1,213 & 1,164 & 1,131 & 1,264 & 1,385 & 925 & 984 & 945 & 1,026 \\
\hline
\end{tabular}


Table 5: Means ${ }^{a}$ of Variables in Benefit Withholding Criteria Analysis

\begin{tabular}{|c|c|c|c|c|c|}
\hline \multirow[b]{2}{*}{ Variable Name } & \multirow[b]{2}{*}{ Definition } & \multirow[b]{2}{*}{$\begin{array}{c}\text { Earnings }>\text { Limit } \\
\text { At Age } 62\end{array}$} & \multicolumn{2}{|c|}{ Sample } & \multirow[b]{2}{*}{$\begin{array}{c}\text { Benefit Decline } \\
\text { Before NRA }\end{array}$} \\
\hline & & & $\begin{array}{c}\text { Earnings }>\text { Limit } \\
\text { At Age } 63\end{array}$ & $\begin{array}{c}\text { Earnings }>\text { Limit } \\
\text { At Age } 64\end{array}$ & \\
\hline Male & 1 if male, 0 otherwise (ow) & $0.52(0.50)$ & $0.48(0.50)$ & $0.51(0.50)$ & $0.52(0.50)$ \\
\hline White & 1 if white, 0 ow & $0.80(0.40)$ & $0.79(0.41)$ & $0.79(0.41)$ & $0.80(0.40)$ \\
\hline No Diploma & 1 if no high school diploma, 0 ow & $0.63(0.48)$ & $0.63(0.48)$ & $0.64(0.48)$ & $0.63(0.48)$ \\
\hline Vocational Training & 1 if vocational training received, 0 ow & $0.28(0.45)$ & $0.27(0.44)$ & $0.28(0.45)$ & $0.28(0.45)$ \\
\hline Bachelors Degree & 1 if Bachelor degree obtained, 0 ow & $0.20(0.40)$ & $0.19(0.39)$ & $0.20(0.40)$ & $0.19(0.39)$ \\
\hline Professional Degree & 1 if professional degree obtained, 0 ow & $0.06(0.23)$ & $0.05(0.23)$ & $0.06(0.24)$ & $0.05(0.23)$ \\
\hline Married & 1 if currently married/living together, 0 ow & $0.78(0.41)$ & $0.80(0.40)$ & $0.79(0.41)$ & $0.82(0.39)$ \\
\hline Primary Respondent & $\begin{array}{l}1 \text { if respondent is financially } \\
\text { knowledgeable person, } 0 \text { ow }\end{array}$ & $0.68(0.47)$ & $0.65(0.48)$ & $0.68(0.47)$ & $0.71(0.45)$ \\
\hline Cognitive Ability & cognitive ability test score (scale: $0-14$ ) & $6.03(2.77)$ & $6.09(2.82)$ & $6.15(2.84)$ & $6.38(2.80)$ \\
\hline Prob. Living to 85 & self-reported probability of living to age 85 & $0.46(0.30)$ & $0.47(0.30)$ & $0.46(0.30)$ & $0.46(0.30)$ \\
\hline Health Limitation Work & 1 if health limitations for work exist, 0 ow & $0.18(0.38)$ & $0.18(0.39)$ & $0.17(0.38)$ & $0.19(0.39)$ \\
\hline No Insurance & 1 if no health insurance, 0 ow & $0.10(0.30)$ & $0.10(0.30)$ & $0.09(0.29)$ & $0.10(0.31)$ \\
\hline Private Insurance & 1 if has private health insurance, 0 ow & $0.20(0.40)$ & $0.21(0.41)$ & $0.20(0.40)$ & $0.25(0.43)$ \\
\hline Net Wealth & total net household wealth (in $\$ 100,000$ s) & $2.39(2.98)$ & $2.64(4.80)$ & $2.68(5.03)$ & $2.90(5.28)$ \\
\hline Private Pension & 1 if has private pension, 0 ow & $0.57(0.50)$ & $0.57(0.50)$ & $0.57(0.50)$ & $0.54(0.50)$ \\
\hline PIA & $\begin{array}{l}\text { monthly benefits if claimed at NRA, from } \\
\text { master beneficiary data (in } 1,000 \text { s } \$ 1991 \text { ) }\end{array}$ & $0.83(0.42)$ & $0.77(0.45)$ & $0.83(0.41)$ & $0.80(0.44)$ \\
\hline Earnings $>$ Limit, 62 & 1 if earnings exceed ET limit when 62,0 ow & $0.07(0.26)$ & & & \\
\hline Earnings $>$ Limit, 63 & 1 if earnings exceed ET limit when 63,0 ow & & $0.13(0.34)$ & & \\
\hline Earnings $>$ Limit, 64 & 1 if earnings exceed ET limit when 64,0 ow & & & $0.11(0.31)$ & \\
\hline Benefit Decline & 1 if benefits decline before NRA, 0 ow & & & & $0.10(0.30)$ \\
\hline Benefit Increase & 1 if benefits increase after NRA, 0 ow & & & & \\
\hline Others & regional dummies; dummies for missing obs. & & $118 ?$ & 165 & 55 \\
\hline
\end{tabular}

Notes: ${ }^{a}$ Based on valid records when respondent turned 62. Standard deviations are presented in parentheses. 
Table 6: Characteristics Associated with Benefit Withholding Criteria. Health and Retirement Survey.

\begin{tabular}{|c|c|c|c|c|}
\hline \multirow[b]{2}{*}{ Variable Name } & \multicolumn{4}{|c|}{ Probit Estimates (Marginal Effects) } \\
\hline & $\begin{array}{c}\text { Earnings }>\text { Limit } \\
\text { At Age } 62\end{array}$ & $\begin{array}{c}\text { Earnings }>\text { Limit } \\
\text { At Age } 63\end{array}$ & $\begin{array}{c}\text { Earnings }>\text { Limit } \\
\text { At Age } 64\end{array}$ & $\begin{array}{c}\text { Benefit Decline } \\
\text { Before NRA }\end{array}$ \\
\hline Male & $\begin{array}{l}0.030^{*} \\
(0.017)\end{array}$ & $\begin{array}{c}0.053^{* * *} \\
(0.020)\end{array}$ & $\begin{array}{c}0.020 \\
(0.019)\end{array}$ & $\begin{array}{c}0.024 \\
(0.020)\end{array}$ \\
\hline White & $\begin{array}{l}-0.006 \\
(0.020)\end{array}$ & $\begin{array}{c}0.014 \\
(0.019)\end{array}$ & $\begin{array}{l}-0.016 \\
(0.022)\end{array}$ & $\begin{array}{l}-0.003 \\
(0.026)\end{array}$ \\
\hline Bachelors Degree & $\begin{array}{c}0.029 \\
(0.022)\end{array}$ & $\begin{array}{l}0.008 \\
(0.024)\end{array}$ & $\begin{array}{l}0.061^{* *} \\
(0.028)\end{array}$ & $\begin{array}{l}-0.031 \\
(0.020)\end{array}$ \\
\hline Professional Degree & $\begin{array}{l}-0.010 \\
(0.024)\end{array}$ & $\begin{array}{c}0.001 \\
(0.039)\end{array}$ & $\begin{array}{l}-0.013 \\
(0.030)\end{array}$ & $\begin{array}{l}0.137^{* *} \\
(0.095)\end{array}$ \\
\hline Married & $\begin{array}{l}-0.007 \\
(0.020)\end{array}$ & $\begin{array}{l}-0.002 \\
(0.021)\end{array}$ & $\begin{array}{l}-0.023 \\
(0.022)\end{array}$ & $\begin{array}{l}-0.037 \\
(0.030)\end{array}$ \\
\hline Primary Respondent & $\begin{array}{c}0.021 \\
(0.016)\end{array}$ & $\begin{array}{c}0.059^{* * *} \\
(0.018)\end{array}$ & $\begin{array}{c}0.017 \\
(0.018)\end{array}$ & $\begin{array}{c}0.008 \\
(0.021)\end{array}$ \\
\hline Cognitive Ability Score & $\begin{array}{l}0.000 \\
(0.003)\end{array}$ & $\begin{array}{l}-0.004 \\
(0.003)\end{array}$ & $\begin{array}{l}-0.001 \\
(0.003)\end{array}$ & $\begin{array}{l}0.006^{*} \\
(0.004)\end{array}$ \\
\hline Prob. Living to 85 & $\begin{array}{c}0.017 \\
(0.033)\end{array}$ & $\begin{array}{c}0.043 \\
(0.038)\end{array}$ & $\begin{array}{l}-0.030 \\
(0.038)\end{array}$ & $\begin{array}{l}-0.016 \\
(0.043)\end{array}$ \\
\hline Health Limitation Work & $\begin{array}{l}-0.036^{* *} \\
(0.014)\end{array}$ & $\begin{array}{c}-0.051^{* *} \\
(0.018)\end{array}$ & $\begin{array}{l}-0.036^{*} \\
(0.018)\end{array}$ & $\begin{array}{c}0.024 \\
(0.027)\end{array}$ \\
\hline No Insurance & $\begin{array}{l}0.053^{*} \\
(0.038)\end{array}$ & $\begin{array}{l}-0.005 \\
(0.028)\end{array}$ & $\begin{array}{l}-0.013 \\
(0.027)\end{array}$ & $\begin{array}{l}-0.042^{*} \\
(0.018)\end{array}$ \\
\hline Private Insurance & $\begin{array}{l}0.030 \\
(0.022)\end{array}$ & $\begin{array}{l}0.035 \\
(0.023)\end{array}$ & $\begin{array}{l}-0.003 \\
(0.021)\end{array}$ & $\begin{array}{l}0.035 \\
(0.025)\end{array}$ \\
\hline Net Wealth & $\begin{array}{c}0.002 \\
(0.002)\end{array}$ & $\begin{array}{l}-0.003 \\
(0.002)\end{array}$ & $\begin{array}{l}-0.001 \\
(0.002)\end{array}$ & $\begin{array}{c}0.002 \\
(0.002)\end{array}$ \\
\hline PIA 65 & $\begin{array}{l}0.045^{*} \\
(0.024)\end{array}$ & $\begin{array}{l}0.055^{* *} \\
(0.027)\end{array}$ & $\begin{array}{c}0.076^{* * *} \\
(0.026)\end{array}$ & $\begin{array}{c}-0.111^{* * *} \\
(0.030)\end{array}$ \\
\hline Private Pension & $\begin{array}{l}-0.031^{*} \\
(0.017)\end{array}$ & $\begin{array}{l}-0.022 \\
(0.018)\end{array}$ & $\begin{array}{c}-0.072^{* * *} \\
(0.019)\end{array}$ & $\begin{array}{c}0.028 \\
(0.020)\end{array}$ \\
\hline $\begin{array}{l}N \\
R^{2} \text { (pseudo) }\end{array}$ & $\begin{array}{c}941 \\
0.124\end{array}$ & $\begin{array}{l}1482 \\
0.100\end{array}$ & $\begin{array}{l}1465 \\
0.069\end{array}$ & $\begin{array}{c}551 \\
0.110\end{array}$ \\
\hline
\end{tabular}

Notes: See text for a detailed explanation of the dependent variables. All models also include controls for region, missing observations on marital status, probability of living to 85, health insurance, and net wealth. Robust standard errors are presented in parentheses. Data are based on waves 1 through 5 of the Health and Retirement Survey. ${ }^{*}$ Statistically significant at the .10 level; ${ }^{* *}$ at the .05 level; ${ }^{* * *}$ at the .01 level. 
Table 7: Simulation Results: 10,000 Simulations of the Dynamic Model

\begin{tabular}{|c|c|c|c|c|c|c|c|c|}
\hline Ages & Full-Time $^{a}$ & Part-Time $^{a}$ & No Work ${ }^{a}$ & Claimers $^{b}$ & Benefits in \$ & $\mathbf{A R F S}^{c}$ & Wages $>\mathbf{E T}^{d}$ & Wages in $\$^{e}$ \\
\hline & \multicolumn{8}{|c|}{ Model 1: Earnings Test as a Tax } \\
\hline Age 60 & $5,762(69.9 \%)$ & $125(2.5 \%)$ & $2,348(28.5 \%)$ & - & - & - & - & - \\
\hline Age 61 & $5,635(69.7 \%)$ & $168(2.1 \%)$ & $2,276(28.2 \%)$ & - & - & - & - & - \\
\hline Age 62 & $5,494(69.1 \%)$ & $0(0 \%)$ & $2,458(30.9 \%)$ & $1,945(25.62 \%)$ & 1,061 & - & 0 & - \\
\hline Age 63 & $3,281(42.2 \%)$ & $221(2.8 \%)$ & $4,266(54.9 \%)$ & $839(11.1 \%)$ & 1,155 & - & 63 & 16,797 \\
\hline Age 64 & $1,052(13.8 \%)$ & $903(11.9 \%)$ & $5,632(74.2 \%)$ & $1,077(14.2 \%)$ & 1,288 & - & 286 & 15,557 \\
\hline Age 65 & $885(11.9 \%)$ & $0(0 \%)$ & $6,536(88.1 \%)$ & $2,478(32.6 \%)$ & 1,366 & - & 461 & 43,899 \\
\hline Age 66 & $1,295(17.9 \%)$ & $500(6.9 \%)$ & $5,945(82.1 \%)$ & $938(12.3 \%)$ & 1,481 & - & 710 & 44,172 \\
\hline \multirow[t]{2}{*}{ Age 67} & $963(13.67 \%)$ & $0(0 \%)$ & $6,082(86.3 \%)$ & $303(3.9 \%)$ & 1,628 & - & 538 & 44,617 \\
\hline & \multicolumn{8}{|c|}{ Model 2: Earnings Test with ARF Adjustments } \\
\hline Age 60 & $5,764(69.9 \%)$ & $127(1.5 \%)$ & $2,344(28.5 \%)$ & - & - & - & - & - \\
\hline Age 61 & $5,636(69.7 \%)$ & $167(2.1 \%)$ & $2,276(28.2 \%)$ & - & - & - & - & - \\
\hline Age 62 & $4,097(51.5 \%)$ & $0(0 \%)$ & $3,855(48.5 \%)$ & $3,722(48 \%)$ & 1,013 & $361(9.69 \%)$ & 446 & 34,717 \\
\hline Age 63 & $1,665(21.4 \%)$ & $1,357(17.5 \%)$ & $4,746(61.1 \%)$ & $1,060(13.7 \%)$ & 1,156 & $374(7.98 \%)$ & 798 & 28,363 \\
\hline Age 64 & $437(5.8 \%)$ & $2,353(31 \%)$ & $4,797(63.2 \%)$ & $800(10.3 \%)$ & 1,277 & $267(4.9 \%)$ & 1,046 & 22,668 \\
\hline Age 65 & $176(2.4 \%)$ & $3,087(41.6 \%)$ & $4,158(56 \%)$ & $1,833(23.7 \%)$ & 1,391 & $9(0.16 \%)$ & 124 & 44,261 \\
\hline Age 66 & $550(7.6 \%)$ & $4,167(57.5 \%)$ & $2,523(34.8 \%)$ & $332(4.3 \%)$ & 1,480 & $9(0.12 \%)$ & 357 & 44,513 \\
\hline Age 67 & $331(4.7 \%)$ & $4,419(62.7 \%)$ & $2,295(32.6 \%)$ & $0(0 \%)$ & - & $9(0.13 \%)$ & 217 & 45,851 \\
\hline
\end{tabular}

Notes: ${ }^{a}$ In numbers, and as percentage of survivors. Survivors for ages 60 to 67 are: 8,235; 8,079; 7,952; 7,768; 7,$587 ; 7,421 ; 7,240 ; 7,045 .{ }^{b}$ Number of First Claimers at that age, and as percentage of the total who ever claimed. ${ }^{c}$ Individuals with Benefits Withheld: In numbers, and as percentage of all claimers at that age. ${ }^{d}$ Individuals who earn above the Earnings Test limits. In the third panel these calculations are just illustrative. ${ }^{e}$ Wages for those who earn above the ET limit. 
Table 8: Policy Experiment: Reform of the Earnings Test. 10,000 Simulations of the Dynamic Model

\begin{tabular}{|c|c|c|c|c|c|c|c|c|}
\hline Ages & Full-Time $^{a}$ & Part-Time $^{a}$ & No Work ${ }^{a}$ & Claimers $^{b}$ & Benefits in \$ & $\mathbf{A R F S}^{c}$ & Wages $>\mathbf{E T}^{d}$ & Wages in \$ \\
\hline & \multicolumn{8}{|c|}{ Model 1: Increase in Earnings Test Limit } \\
\hline Age 60 & $5,766(70 \%)$ & $126(1.5 \%)$ & $2,343(28.5 \%)$ & - & - & - & - & - \\
\hline Age 61 & $5,635(69.7 \%)$ & $174(2.1 \%)$ & $2,278(28.2 \%)$ & - & - & - & - & - \\
\hline Age 62 & $3,764(47.3 \%)$ & $0(0 \%)$ & $4,188(52.6 \%)$ & $4,350(56 \%)$ & 1,054 & $72(1.6 \%)$ & 322 & 42,016 \\
\hline Age 63 & $1,557(20 \%)$ & $1,898(24.4 \%)$ & $4,313(55.5 \%)$ & $714(9.2 \%)$ & 1,192 & $100(2 \%)$ & 308 & 45,480 \\
\hline Age 64 & $496(6.5 \%)$ & $2,523(32.2 \%)$ & $4,568(60.2 \%)$ & $676(8.7 \%)$ & 1,285 & $72(1.3 \%)$ & 258 & 45,216 \\
\hline Age 65 & $214(2.9 \%)$ & $3,169(42.7 \%)$ & $4,038(54.4 \%)$ & $1,711(22 \%)$ & 1,393 & $17(0.02 \%)$ & 152 & 44,628 \\
\hline Age 66 & $591(8.2 \%)$ & $4,143(57.2 \%)$ & $2,506(34.6 \%)$ & $318(4.1 \%)$ & 1,480 & $17(0.02 \%)$ & 383 & 44,708 \\
\hline \multirow[t]{2}{*}{ Age 67} & $365(5.1 \%)$ & $4,393(62.3 \%)$ & $2,287(32.5 \%)$ & $0(0 \%)$ & - & $17(0.02 \%)$ & - & - \\
\hline & \multicolumn{8}{|c|}{ Model 2: Decrease in Benefit Tax Rate } \\
\hline Age 60 & $5,763(69.9 \%)$ & $127(1.5 \%)$ & $2,345(28.5 \%)$ & - & - & - & - & - \\
\hline Age 61 & $5,636(69.7 \%)$ & $167(2.1 \%)$ & $2,276(28.2 \%)$ & - & - & - & - & - \\
\hline Age 62 & $4,089(51.4 \%)$ & $0(0 \%)$ & $3,863(48.6 \%)$ & $3,552(45.9 \%)$ & 1,035 & $136(3.8 \%)$ & 267 & 34,153 \\
\hline Age 63 & $1,610(20.7 \%)$ & $1,388(17.8 \%)$ & $4,770(61.4 \%)$ & $1,100(14.2 \%)$ & 1,162 & $156(3.4 \%)$ & 617 & 25,621 \\
\hline Age 64 & $361(4.8 \%)$ & $2,342(30.9 \%)$ & $4,884(64.4 \%)$ & $856(11.1 \%)$ & 1,286 & $136(2.6 \%)$ & 939 & 21,233 \\
\hline Age 65 & $197(2.6 \%)$ & $3,010(40.6 \%)$ & $4,214(56.8 \%)$ & $1,887(24.4 \%)$ & 1,393 & $17(0.24 \%)$ & 146 & 45,291 \\
\hline Age 66 & $537(7.4 \%)$ & $4,169(57.6 \%)$ & $2,534(35 \%)$ & $343(4.4 \%)$ & 1,483 & $17(0.23 \%)$ & 349 & 44,591 \\
\hline \multirow[t]{2}{*}{ Age 67} & $345(4.9 \%)$ & $4,407(62.5 \%)$ & $2,293(32.5 \%)$ & $0(0 \%)$ & - & $17(0.24 \%)$ & - & - \\
\hline & \multicolumn{8}{|c|}{ Model 3: Removal of the Earnings Test } \\
\hline Age 60 & $5,766(70 \%)$ & $126(1.6 \%)$ & $2,343(28.4 \%)$ & - & - & - & - & - \\
\hline Age 61 & $5,635(69.8 \%)$ & $166(2 \%)$ & $2,278(28.2 \%)$ & - & - & - & - & - \\
\hline Age 62 & $3,341(42 \%)$ & $0(0 \%)$ & $4,611(58 \%)$ & $4,999(64 \%)$ & 1,087 & - & 941 & 33,439 \\
\hline Age 63 & $1,470(18.9 \%)$ & $2,210(28.4 \%)$ & $4,088(52.6 \%)$ & $611(7.8 \%)$ & 1,197 & - & 1,411 & 27,842 \\
\hline Age 64 & $641(8.4 \%)$ & $2,775(36.6 \%)$ & $4,171(54.9 \%)$ & $608(7.8 \%)$ & 1,287 & - & 1,497 & 25,251 \\
\hline Age 65 & $413(5.6 \%)$ & $3,370(45.4 \%)$ & $3,638(49 \%)$ & $1,358(17.4 \%)$ & 1,383 & - & 271 & 45,218 \\
\hline Age 66 & $641(8.8 \%)$ & $4,165(57.5 \%)$ & $2,434(33.6 \%)$ & $230(2.9 \%)$ & 1,477 & - & 413 & 44,418 \\
\hline Age 67 & $416(5.9 \%)$ & $4,347(61.7 \%)$ & $2,282(32.4 \%)$ & $0(0 \%)$ & - & - & - & - \\
\hline
\end{tabular}

Notes: ${ }^{a}$ In numbers, and as percentage of survivors. The number of survivors for ages 60 to 67 are the same as in the previous table. ${ }^{b}$ Number of First Claimers at that age, and as percentage of the total who ever claimed. ${ }^{c}$ Individuals with Benefits Withheld: In numbers, and as percentage of all claimers at that age. ${ }^{d}$ Individuals who earn above the Earnings Test limits. In the third panel these calculations are just illustrative. 